\title{
IMPERFECT COMPETITION AND QUALITY SIGNALING
}

by

Andrew F. Daughety and Jennifer F. Reinganum

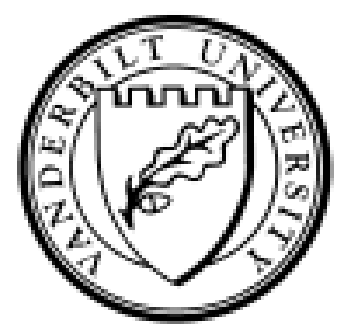

Working Paper No. 05-W20

August 2005

\section{DEPARTMENT OF ECONOMICS \\ VANDERBILT UNIVERSITY \\ NASHVILLE, TN 37235}

www.vanderbilt.edu/econ 


\section{Imperfect Competition and Quality Signaling Andrew F. Daughety* \\ Jennifer F. Reinganum* \\ Department of Economics \\ and Law School \\ Vanderbilt University \\ Nashville, TN 37235 \\ andrew.f.daughety@vanderbilt.edu \\ jennifer.f.reinganum@vanderbilt.edu}

June 2005

Revised: August 2005

* This research was supported by NSF Grant SES-0239908. 


\begin{abstract}
We examine the interplay of imperfect competition and incomplete information in the context of price competition among firms producing horizontally- and vertically-differentiated substitute products. We find that incomplete information about vertical quality (e.g., consumer satisfaction) that is signaled via price softens price competition, and that imperfect competition can reduce the degree to which firms distort their prices to signal their types (relative to what a monopolist would do). We show that low-quality firms always prefer playing the incomplete information game to the full-information analog: their prices are higher and so are their profits. Moreover, for "high-value" markets, if the proportion of high-quality firms is great enough, highquality firms also prefer incomplete information to full information. We find conditions such that an increase in the loss to consumers associated with consuming the low-quality product may perversely benefit low-quality firms. We discuss the implications of our analysis for recent tort reform proposals, incentives for the diffusion of general innovation to product-specific improvements, and professional licensing.
\end{abstract}




\section{Introduction}

In this paper we examine the interplay of imperfect competition and incomplete information in the context of a multi-firm industry producing horizontally-differentiated substitute products with an associated vertical quality measure, such as consumer satisfaction with a firm's product. We find that incomplete information about quality that is signaled via price softens price competition by firms, and that imperfect competition can reduce the degree to which firms distort their prices to signal their (vertically-differentiated) types relative to what a monopolist would do. In fact, we show that low-quality firms always prefer playing the incomplete information game to the fullinformation analog: their prices are higher and so are their profits. Moreover, for "high-value" markets (suitably defined), if the proportion of high-quality firms is great enough, high-quality firms also prefer incomplete information to full information. This is in contrast to the results for a monopolist, who would prefer full information so as to avoid the price distortion associated with signaling.

Other unexpected results of the interplay between imperfect competition and incomplete information also emerge; these results reflect both a firm's best-response behavior vis-a-vis its rivals and its incentive compatibility conditions vis-a-vis its own alter ego. For high-value markets, equilibrium prices, quantities, and profits for both types of firms are increasing in the proportion of high-quality firms; this parameter does not affect equilibrium play in the monopoly signaling model or in the full-information model. In equilibrium, low-quality firms produce greater output than do high-quality firms, a reversal of the result that obtains under full-information imperfect competition. Finally, an increase in the loss borne by consumers due to the low-quality product can (for portions of the parameter space) perversely increase the low-quality firm’s price, quantity, and profits; this effect also does not arise in the monopoly signaling model or in the full-information model. This 
last result suggests that recent proposals for tort reform may actually increase the likelihood of harm and lawsuits, that innovations which provide quality improvements may be resisted by firms in an industry, and that licensing of professional services can result in increased competition and lower prices.

Plan of the Paper

In Section 2 we provide a brief review of the literature. Section 3 provides the model and results. Section 4 discusses some implications and applications of the model. Section 5 provides a brief summary and conclusions. Supplementary material, including complex formulae and selected proofs, is contained in the Appendix. ${ }^{1}$

\section{Related Literature}

There are several strands of literature that are related to this work. One body of related work involves a monopolist using price to signal product quality. Bagwell and Riordan (1991) examine a two-type model in which a high-quality product is more costly to produce than is a low-quality product (we adopt this formulation below, but with multiple firms). In equilibrium, the low-quality firm chooses its full-information price, while the high-quality firm distorts its price upward relative to the full-information price for high quality. ${ }^{2}$ Daughety and Reinganum (1995) provide a model with a continuum of types in which quality is viewed as product safety. When a product fails and harms a consumer, the liability system determines how the associated losses are allocated across the

1 Proofs of Propositions 1, 3, and 4 are provided. Proofs of Propositions 2, 5, and 6 are straightforward but tedious, and are omitted (example calculations are provided for Proposition 6).

${ }^{2}$ Bagwell (1992) conducts a related analysis of a monopolist producing a product "line.” 
parties. In equilibrium, higher prices signal safer products when the consumer bears a sufficiently high portion of the loss, while lower prices signal safer products when the firm bears a sufficiently high portion of the loss. Daughety and Reinganum (2005) consider a model in which quality is a safety attribute and the firm may engage in confidential settlement of lawsuits. Following firstperiod production, the monopolist learns its product's safety through harmed consumers who seek compensation. The firm settles lawsuits confidentially, which (potentially) reduces the viability of suits and prevents future consumers from directly observing product safety. Although confidentiality lowers the firm's expected liability costs, it also depresses demand for its product. Daughety and Reinganum (2005) characterize when this trade-off induces the firm to prefer confidentiality versus a regime of openness (in which suits cannot be settled confidentially, and thus future consumers directly observe the product’s safety).

There is a strand of the literature which considers price and advertising as joint signals of product quality. For example, Milgrom and Roberts (1986) provide a two-type monopoly model in which the cost of high quality may be higher or lower than that of low quality, and repeat sales are an important attribute of the model. They identify various conditions under which high quality may be signaled with a high price alone, a low price alone, or a combination of price and advertising expenditure. $^{3}$ Hertzendorf and Overgaard (2001b) and Fluet and Garella (2002) examine very similar duopoly models in which firms use price and advertising expenditure to signal their qualities.

${ }^{3}$ Hertzendorf (1993) argues that, if advertising is stochastically-observed, price and advertising expenditure will never be used in combination. Another interesting paper is Linnemer (1998), in which a firm uses price and advertising to signal to two different audiences: it signals its product quality to consumers and its marginal cost to a potential entrant. 
While consumers do not know either firm's quality, both firms know both firms' qualities. ${ }^{4}$ Moreover, consumers do not have a preference between the two goods, provided they are of the same quality and charge the same price (i.e., there is no horizontal differentiation). In equilibrium, price alone can signal quality when vertical differentiation is substantial, but otherwise advertising is required as well. When advertising is not used, quality is signaled with upward-distorted prices, but when advertising is used, prices may be driven below their full-information levels.

Daughety and Reinganum (2004) provide a duopoly model in which each firm uses its price to signal its product quality; this model differs from those above in three important respects. First, only price can be used to signal quality. Second, the products on offer are differentiated, both horizontally and, possibly, vertically. Third, each firm's quality is its private information. This information structure arises naturally in the context of quality as safety under a regime that permits confidential settlement of lawsuits (as described above). By settling confidentially with consumers harmed in the current period, the firm prevents future consumers and its rival from learning its quality. In the next period, each firm has private information about its own quality, which sets up the signaling game in which a firm's price may reveal its product quality. That paper employs a post-sale subgame involving tort liability, and therefore makes other simplifying assumptions to enhance tractability; in particular, a fixed number of consumers distributed along a line is assumed, with each consumer demanding a single unit. Moreover, it is assumed that the market is always

${ }^{4}$ See also Hertzendorf and Overgaard (2001a) for a duopoly model in which firms can only use price to signal quality; again, both firms know both firms’ qualities. Harrington (1987), Bagwell and Ramey (1991), and Orzach and Tauman (1996) consider limit pricing models in which two or more incumbent firms with common private information about production costs attempt to deter entry using price as a signal of cost. These papers are more closely-related to the models of Hertzendorf and Overgaard, and Fluet and Garella, than to ours. 
fully covered; that is, every consumer buys a unit of the good. As a consequence, the market size is fixed exogenously.

A special case of the model described above is one wherein consumers bear the full loss associated with low quality; this can be interpreted as a “consumer satisfaction” model as introduced in Milgrom and Roberts (1986). In a consumer satisfaction model, the consumer simply receives lower utility from low-quality products than from high-quality products but, because utility is unverifiable, no compensation can be promised (e.g., a warranty cannot be used to insure the consumer against a loss of utility from low quality). ${ }^{5}$

The current paper also considers a consumer satisfaction model in which each firm has private information about its product quality, but employs a more general demand and market structure. Each consumer has a linked system of demand functions for n differentiated products (each produced by a single firm), and each firm will non-cooperatively choose its price given its private information. Thus, the size of each firm's market, as well as the size of the total market for all n differentiated products, is determined endogenously. This means that we are able to examine the effect of changes in the number of firms, in the degree of substitutability of the products, and in the consumer’s willingness-to-pay on equilibrium behavior.

Other (more tangentially-related) literatures include those involving quality-guaranteeing prices and those involving disclosure of quality. In the quality-guaranteeing price literature (dating back to the early 1980's; see, e.g., Klein and Leffler, 1981), firms choose their qualities, as well as

${ }^{5}$ If the consumer's loss were verifiable then a firm could offer a warranty contract specifying the consumer's extent of recovery in the event of this loss. Since the warranty contract is endogenous, warranties could serve as another route via which quality could be signaled (see Lutz, 1989, for such a model). 
their prices, while consumers observe only the prices. Equilibrium is characterized by a price premium that is sufficient to induce firms subsequently to provide high quality. Thus, unobservable quality relaxes price competition. A recent example is Bester (1998), who relates the magnitude of this effect to the degree of endogenous horizontal product differentiation. Levin, Peck and Ye (2005) provide a model in which two firms have private information about the quality of their respective products, but can engage in costly disclosure. Consumers are located along a line between the two products, reflecting horizontal product differentiation. The cost of production is independent of quality and thus no signaling is possible. In equilibrium, firms engage in sociallyexcessive disclosure. The current paper differs from the quality-guaranteeing price literature because Nature chooses firm quality in our model, and differs from the disclosure literature because firms cannot credibly disclose quality and must instead resort to signaling.

Finally, there is also a small literature on non-cooperative signaling when each firm has private information about its cost of production. The most closely-related paper is Mailath (1989), which provides an n-firm oligopoly model with linear demand and constant marginal costs in which firms produce horizontally-differentiated products and engage in non-cooperative price competition across two periods. ${ }^{6}$ A firm's first-period price can signal its (privately observed) marginal cost of production, which influences its rivals' pricing behavior in the second period. ${ }^{7}$ Consumers have no

${ }^{6}$ Gal-Or (1988) also considers a two-period model in which firms learn about their costs, and those of their rivals, over time; her paper specifically omits consideration of the signaling problem. Mailath (1988) establishes conditions guaranteeing the existence of separating equilibria in abstract two-period games with simultaneous signaling.

${ }^{7}$ In a similar vein, Martin (1995) considers a two-period model in which two incumbent firms signal their privately known marginal costs, both to each other and to a potential entrant. When firms use price strategies in a horizontally-differentiated products model, an incumbent firm would like its incumbent rival to perceive it as high-cost, but this perception also invites entry. This 
inference problem, since they care only about prices, not marginal costs. Mailath finds that firms' prices are upward-distorted (in order to persuade rivals to price higher in the second period) relative to the "non-signaling benchmark," which retains incomplete information in the first period, but assumes that the firms' types are exogenously revealed prior to the second period (so the signaling motive is removed).

Although we also use a horizontally-differentiated-products model with linear demand and constant marginal costs, our model differs from that of Mailath in other ways. First, we consider a one-period model wherein each firm signals its quality to consumers, rather than to its rivals. Second, a firm's product quality (type) affects both its constant marginal cost of production and the demand curve it faces, because product quality also reflects vertical differentiation. Finally, in our model the non-signaling benchmark is the full-information outcome in which both rivals and consumers observe product quality directly. Like Mailath, we find that equilibrium prices are upward-distorted relative to our (full-information) benchmark prices.

\section{Model Set-Up and Results}

Our model employs a representative consumer, who consumes some of each product, and n firms, each of whom produces one of the products, under conditions of constant marginal costs. The products are horizontally- and vertically-differentiated, where the quality of the product (the vertical attribute) takes on two possible levels (high and low). In period one, Nature independently

can result in pooling equilibria. Das Varma (2003) considers a model in which the auction of a cost-reducing innovation precedes market competition. Each firm bids more aggressively for the innovation in order to persuade its rivals that, should it win the auction, it will be very competitive in the subsequent market. 
draws a type for each firm from a common distribution and each firm observes its type. In period two, firms simultaneously choose prices. Finally, in period three, the representative consumer observes all prices and buys quantities of the products accordingly. In the incomplete-information model, firms do not observe the types of other firms, and consumers do not directly observe the type of any firm. In the full-information model, firms and consumers observe all the types in period two before firms choose prices. In all settings we restrict the analysis to interior equilibria.

\section{$\underline{\text { Consumer Model }}$}

To keep things as simple as possible, we consider a single consumer ${ }^{8}$ who consumes a variety of goods; products $1,2, \ldots, n$ are differentiated substitute goods and good $n+1$ is a numeraire good. Each product is made by a different firm, and we assume there are $n \geq 2$ products. Products $1,2, \ldots, \mathrm{n}$ may be of either high or low quality (signified by $\mathrm{H}$ or $\mathrm{L}$, respectively). Let $\theta_{\mathrm{i}}$ be an indicator function which takes on the value 1 when product $\mathrm{i}$ is of high quality and the value 0 when product $\mathrm{i}$ is of low quality. We assume that the consumer derives utility from the product, less a loss per unit consumed, which is zero for the high-quality good and $\delta>0$ for the low-quality good. ${ }^{9}$ The occurrence of this loss is unverifiable (e.g., an uncomfortable mattress, a lazy real estate agent, or a mediocre meal) and therefore cannot be covered by a warranty, or compensated via a lawsuit. Nature determines product quality independently for each firm, and $\operatorname{Pr}\{\mathrm{H}\}$ is given by $\lambda \in(0,1) .{ }^{10}$

${ }^{8}$ Given constant returns to scale, the same results apply for multiple identical consumers.

${ }^{9}$ One could generalize the model to allow $\theta_{\mathrm{i}}$ to take on values between zero and one, and then interpret $\theta_{\mathrm{H}}$ as the probability that a product $\mathrm{i}$ of high quality does not result in a loss of $\delta$, and $\theta_{\mathrm{L}}\left(<\theta_{\mathrm{H}}\right)$ as the probability that a product of low quality does not result in a loss of $\delta$. In this case, a higher-quality product is less likely to result in a loss of $\delta$, but both qualities of products can fail to provide complete satisfaction to the customer.

${ }^{10}$ For certain results we will consider limits where $\lambda$ goes to zero or one. 
The consumer enjoys higher utility from consuming a high-quality product $i$ than a low-quality product i, but both versions of product i are worthwhile. In particular, we assume the consumer's utility function is quadratic in the n differentiated products, with the parameters $\alpha>0, \beta>0$, and $\gamma>0$ :

$$
\mathrm{U}\left(\mathrm{q}_{1}, \ldots, \mathrm{q}_{\mathrm{n}}\right)=\sum_{\mathrm{i}}\left[\alpha-\left(1-\theta_{\mathrm{i}}\right) \delta\right] \mathrm{q}_{\mathrm{i}}-1 / 2\left(\sum_{\mathrm{i}} \beta \mathrm{q}_{\mathrm{i}}^{2}+\sum_{\mathrm{i}} \sum_{\mathrm{j} \neq \mathrm{i}} \gamma \mathrm{q}_{\mathrm{i}} \mathrm{q}_{\mathrm{j}}\right),
$$

where $\gamma$ is the degree of product substitution between any two products in the class of interest. We take $\gamma$ to lie in the interval $(0, \beta) .{ }^{11}$ Product quality enters through the linear coefficient on $\mathrm{q}_{\mathrm{i}}$; this coefficient is $\alpha$ if product $\mathrm{i}$ is of high quality but falls to $\alpha-\delta$ if product $\mathrm{i}$ is of low quality.

The consumer with income I chooses $\left(\mathrm{q}_{1}, \ldots, \mathrm{q}_{\mathrm{n}}\right)$ so as to maximize her utility of consumption (the consumption of the numeraire good is found as the residual):

$$
\max \mathrm{q}_{1}, \ldots, \mathrm{q}_{\mathrm{n}}\left\{\mathrm{U}\left(\mathrm{q}_{1}, \ldots, \mathrm{q}_{\mathrm{n}}\right)+\mathrm{I}-\sum_{\mathrm{i}} \mathrm{p}_{\mathrm{i}} \mathrm{q}_{\mathrm{i}}\right\} .
$$

Thus, for positive demands, the inverse demand function for product i is:

$$
p_{i}\left(q_{1}, \ldots, q_{n}\right)=\alpha-\left(1-\theta_{i}\right) \delta-\beta q_{i}-\gamma \sum_{j \neq i} q_{j}
$$

Since we are interested in firms using price strategies to signal their product quality, we solve for the ordinary demand functions:

$$
\mathrm{q}_{\mathrm{i}}\left(\mathrm{p}_{1}, \ldots, \mathrm{p}_{\mathrm{n}}\right)=\mathrm{a}-\mathrm{b}\left(1-\theta_{\mathrm{i}}\right) \delta+\mathrm{g} \sum_{\mathrm{j} \neq \mathrm{i}}\left(1-\theta_{\mathrm{j}}\right) \delta-b \mathrm{p}_{\mathrm{i}}+\mathrm{g} \sum_{\mathrm{j} \neq \mathrm{i}} \mathrm{p}_{\mathrm{j}},
$$

where $a \equiv \alpha /(\beta+(n-1) \gamma), b \equiv(\beta+(n-2) \gamma) /(\beta-\gamma)(\beta+(n-1) \gamma)$, and $g \equiv \gamma /(\beta-\gamma)(\beta+(n-1) \gamma)$.

These represent the consumer's demand functions when quality is observable. When quality is unobservable to the consumer, she will have perceptions of product quality, which we will denote by $\tilde{\theta}_{j}, j=1,2, \ldots, n$. Then equation (1), modified by substituting perceived for true qualities, still

${ }^{11}$ Note that if $\gamma=0$, then each product is independent of each other product, and each firm has a monopoly in its product market. 
describes the consumer's demand functions. We will later discuss in greater detail how the consumer's perceptions are formed based on observed prices.

\section{$\underline{\text { Firm and Industry Model }}$}

For simplicity, we assume that each firm has constant marginal costs which depend on the quality of its product. The cost of producing a unit of a low-quality product is normalized to zero, ${ }^{12}$ and the cost of producing a unit of a high-quality product is $\mathrm{k}>0$. We also assume that $\delta>\mathrm{k}$, so that the additional utility generated by a unit of a high-quality product justifies its incremental production cost (i.e., a consumer would be willing to pay k to receive higher quality, thus avoiding the loss $\delta)$.

A firm's profits can be written as a function of its product's true quality, its product's perceived quality (from the consumer's point of view) and its price, given the perceived qualities and prices of its rivals. If quality were observable, then the perceived qualities would coincide with the true qualities. However, perceived quality may differ from true quality if quality is not observable. Then profits for firm i, when it charges price $\mathrm{p}_{\mathrm{i}}$, its true quality is $\theta_{\mathrm{i}}$ and its perceived quality is $\tilde{\theta}_{\mathrm{i}}$ (and the vector of other firms' prices is $\mathrm{p}_{-\mathrm{i}}$ and the vector of other firms' perceived qualities is $\tilde{\theta}_{-\mathrm{i}}$ ) can be written as:

$$
\pi_{i}\left(p_{i}, \theta_{i}, \tilde{\theta}_{i} \mid p_{-i}, \tilde{\theta}_{-i}\right)=\left(p_{i}-k \theta_{i}\right)\left(a-b\left(1-\tilde{\theta}_{i}\right) \delta+g \sum_{j \neq i}\left(1-\tilde{\theta}_{j}\right) \delta-b p_{i}+g \sum_{j \neq i} p_{j}\right) .
$$

Thus, firm i's profits are a product of the true price-cost margin and the consumer's demand for product i, which is based on prices and her perceptions of quality.

We want to characterize a symmetric separating perfect Bayesian equilibrium for this game,

${ }^{12}$ We generalize this cost structure to allow positive costs for the low-quality product later in the paper in discussing one of our applications. 
wherein each firm's product quality is its private information; that is, firm i's product quality is unknown both to the consumer and to firm i's rivals. ${ }^{13}$ Suppose that all other firms employ the same separating pricing rule $\mathrm{p}^{*}(\theta)$; that is, $\mathrm{p}^{*}(1) \neq \mathrm{p}^{*}(0)$. Then because this is a separating strategy, firm i predicts that the consumer's perception of all rival firms' product qualities will be correct. Moreover, firm i also predicts that each of its rivals will charge the price $\mathrm{p}^{*}(1)$ with probability $\lambda$ and the price $\mathrm{p}^{*}(0)$ with probability 1 - $\lambda$. Thus, firm i’s expected profits, when it charges price $\mathrm{p}_{\mathrm{i}}$, its true quality is $\theta_{i}$ and its perceived quality is $\tilde{\theta}_{i}$ (and all rival firms use the separating strategy $\left.\mathrm{p}^{*}(\bullet)\right)$ can be written as:

$$
\mathrm{E}_{-\mathrm{i}}\left\{\pi_{\mathrm{i}}\left(\mathrm{p}_{\mathrm{i}}, \theta_{\mathrm{i}}, \tilde{\theta}_{\mathrm{i}} \mid \mathrm{p}_{-\mathrm{i}}, \theta_{-\mathrm{i}}\right)\right\}=\left(\mathrm{p}_{\mathrm{i}}-\mathrm{k} \theta_{\mathrm{i}}\right) \mathrm{E}_{-\mathrm{i}}\left\{\mathrm{a}-\mathrm{b}\left(1-\tilde{\theta}_{\mathrm{i}}\right) \delta+\mathrm{g} \sum_{\mathrm{j} \neq \mathrm{i}}\left(1-\theta_{\mathrm{j}}\right) \delta-\mathrm{b} \mathrm{p}_{\mathrm{i}}+\mathrm{g} \sum_{\mathrm{j} \neq \mathrm{i}} \mathrm{p}^{*}\left(\theta_{\mathrm{j}}\right)\right\},
$$

where $E_{-i}$ denotes the expectation with respect to the vector of rivals' product quality $\theta_{-\mathrm{i}}$. Since the second term above is linear in the rivals' types and prices, and the types are identically and independently drawn, this term is simply a - b(1 - $\left.\widetilde{\theta}_{\mathrm{i}}\right) \delta+\mathrm{g}(\mathrm{n}-1)(1-\lambda) \delta-b p_{\mathrm{i}}+\mathrm{g}(\mathrm{n}-1) \mathrm{E}\left(\mathrm{p}^{*}\right)$, where $\mathrm{E}\left(\mathrm{p}^{*}\right) \equiv \lambda \mathrm{p}^{*}(1)+(1-\lambda) \mathrm{p}^{*}(0)$. Thus, firm i's expected profits can be written as:

$$
\Pi_{\mathrm{i}}\left(\mathrm{p}_{\mathrm{i}}, \theta_{\mathrm{i}}, \widetilde{\theta}_{\mathrm{i}} \mid \mathrm{E}\left(\mathrm{p}^{*}\right)\right) \equiv\left(\mathrm{p}_{\mathrm{i}}-\mathrm{k} \theta_{\mathrm{i}}\right)\left(\mathrm{a}-\mathrm{b}\left(1-\tilde{\theta}_{\mathrm{i}}\right) \delta+\mathrm{g}(\mathrm{n}-1)(1-\lambda) \delta-\mathrm{b} \mathrm{p}_{\mathrm{i}}+\mathrm{g}(\mathrm{n}-1) \mathrm{E}\left(\mathrm{p}^{*}\right)\right) \text {. }
$$

To formalize the notion of the consumer's perception of quality, we define a belief function which specifies the type (high- or low-quality) that the consumer assigns to a firm. The firms (of a given type) are completely symmetric, so it is natural to impose a symmetry assumption. Moreover, firm types are independently drawn and no firm has any information about its rivals’ types when it chooses its price, so its price cannot vary with the rivals' types, and hence its price cannot convey any information about the rivals' types. Thus, it is also natural to assume that the

13 In fact, we show that the separating equilibrium we discuss is the only symmetric separating equilibrium to survive refinement under the Intuitive Criterion. Moreover, this same refinement eliminates all (pure) pooling equilibria. 


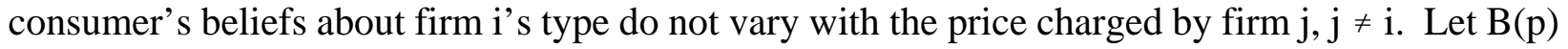
be the belief function; thus, if firm i charges $\mathrm{p}_{\mathrm{i}}$, then it is inferred to be of type $\mathrm{B}\left(\mathrm{p}_{\mathrm{i}}\right)$. This belief function depends only on the price chosen by firm i, and it is the same function for all firms, so it reflects the preceding discussion of symmetry and invariance with respect to rivals’ prices.

Finally, we need to restrict the parameters for the analysis so as to guarantee an interior equilibrium. Define the firm's true-type-dependent marginal costs: $c_{\mathrm{s}} \equiv \theta_{\mathrm{i}} \mathrm{k}$, where $\mathrm{s}=\mathrm{L}, \mathrm{H}$ and $\theta_{\mathrm{i}}$ $=0$ if the firm is of type $\mathrm{L}$ and $\theta_{\mathrm{i}}=1$ if the firm is of type $\mathrm{H}$. The firm's demand (based on its perceived type $)$ is $\left(d_{t}-p\right) b$, where $d_{t} \equiv\left\{a-b\left(1-\widetilde{\theta}_{i}\right) \delta+g(n-1)(1-\lambda) \delta+g(n-1) E\left(p^{*}\right)\right\} / b, t=L, H$. Thus we can use the short-hand notation $\Pi_{s t}=\left(p-c_{s}\right) b\left(d_{t}-p\right)$, for $s, t=L, H$.

For some parameter combinations, one or both types might not be able to pick prices that yield positive profits; under such parameter combinations, agents would potentially infer that the prior probability of a firm being an H-type was not $\lambda$, and should be updated, something that is not of particular interest to the current analysis. To ensure that there is always a profitable price for a firm, regardless of the consumer's perceptions of quality and regardless of the rival firm's expected price, we need $d_{t}>c_{s}$ for all s, t. The tightest such constraint is $d_{L}>c_{H}$; that is, $\{a-b \delta+g(n-1)(1-$ $\left.\lambda) \delta+g(n-1) E\left(p^{*}\right)\right\} / b>k$. Recognizing that $\lambda$ may be arbitrarily close to $1, \mathrm{E}\left(\mathrm{p}^{*}\right)$ may be arbitrarily close to zero, and k (though smaller) may be arbitrarily close to $\delta$, we employ the following sufficient condition, which we maintain throughout the paper.

Assumption 1. a $>2 \delta b$; that is, $\alpha(\beta-\gamma)>2 \delta(\beta+(n-2) \gamma)$.

In equilibrium, each firm maximizes its expected profits, given the pricing functions of its 
rivals and given the consumer's belief function, and the consumer's beliefs are consistent with the equilibrium pricing function used by the firms. This is formalized in the following definition.

Definition. A symmetric separating perfect Bayesian equilibrium consists of a pair of prices $\left(\mathrm{p}^{*}(0), \mathrm{p}^{*}(1)\right) \equiv\left(\mathrm{P}_{\mathrm{L}}, \mathrm{P}_{\mathrm{H}}\right)$ and beliefs $\mathrm{B}^{*}(\mathrm{p})$ such that, for $\mathrm{i}=1,2, \ldots, \mathrm{n}$ :

(i) $\Pi_{i}\left(P_{L}, 0,0 \mid E\left(p^{*}\right)\right) \geq \max _{p} \Pi_{i}\left(p, 0, B^{*}(p) \mid E\left(p^{*}\right)\right)$;

(ii) $\Pi_{\mathrm{i}}\left(\mathrm{P}_{\mathrm{H}}, 1,1 \mid \mathrm{E}\left(\mathrm{p}^{*}\right)\right) \geq \max _{\mathrm{p}} \Pi_{\mathrm{i}}\left(\mathrm{p}, 1, \mathrm{~B}^{*}(\mathrm{p}) \mid \mathrm{E}\left(\mathrm{p}^{*}\right)\right)$;

(iii) $\mathrm{B}^{*}\left(\mathrm{P}_{\mathrm{L}}\right)=0, \mathrm{~B}^{*}\left(\mathrm{P}_{\mathrm{H}}\right)=1$;

(iv) $\mathrm{E}\left(\mathrm{p}^{*}\right)=\lambda \mathrm{P}_{\mathrm{H}}+(1-\lambda) \mathrm{P}_{\mathrm{L}}$.

Part (i) says that a firm that has a low-quality product, and is perceived to have a low-quality product, would prefer to charge $\mathrm{P}_{\mathrm{L}}$ rather than its best alternative price, given the consumer's belief function and the expected rival price. Part (ii) says that a firm that has a high-quality product, and is perceived to have a high-quality product, would prefer to charge $\mathrm{P}_{\mathrm{H}}$ rather than its best alternative price, given the consumer's belief function and the expected rival price. These conditions reflect both a firm's best-response behavior vis-a-vis its rivals and its incentive compatibility conditions vis-a-vis its own alter ego. Part (iii) says that the consumer's beliefs are correct in equilibrium; she believes the product is of low quality when the firm charges $\mathrm{P}_{\mathrm{L}}$ and she believes the product is of high quality when the firm charges $\mathrm{P}_{\mathrm{H}}$. Finally, part (iv) says that the prior-weighted expectation of $\mathrm{P}_{\mathrm{H}}$ and $\mathrm{P}_{\mathrm{L}}$ equals the expected rival price; that is, it is a mutual best response for all firms to play the price strategy $\left(\mathrm{P}_{\mathrm{L}}, \mathrm{P}_{\mathrm{H}}\right)$. 


\section{$\underline{\text { Results }}$}

In this section we provide the primary results for the model above, along with a discussion of the intuition for the results. The comparative statics results (which are explored in Propositions 2, 5, and 6) are summarized in Table 1 near the end of the section. Unless otherwise specified, all references to equilibrium entities (i.e., prices, quantities, and profits) are interim versions (that is, each firm knows its type, but not the type of any rival).

The following proposition indicates that there always exists a symmetric perfect Bayesian equilibrium (PBE) in which the two types separate. Moreover, by employing a refinement (the Intuitive Criterion; see the Appendix) we select one separating equilibrium and show that this is the only symmetric equilibrium (separating or pooling) which survives refinement. Due to the complexity of the algebra of expressing the equilibrium prices, quantities and profits, we leave these details to the Appendix.

Proposition 1 (Existence of a Unique Refined Equilibrium). There is a unique (refined) symmetric separating perfect Bayesian equilibrium consisting of a pair of prices $\left(\mathrm{P}_{\mathrm{L}}, \mathrm{P}_{\mathrm{H}}\right)$, with $\mathrm{P}_{\mathrm{H}}>\mathrm{P}_{\mathrm{L}}$, and supporting beliefs $\mathrm{B}^{*}(\mathrm{p})$, with $\mathrm{B}^{*}(\mathrm{p})=0$ when $\mathrm{p}<\mathrm{P}_{\mathrm{H}}$, and $\mathrm{B}^{*}(\mathrm{p})=1$ when $\mathrm{p} \geq \mathrm{P}_{\mathrm{H}}$. Moreover, $\mathrm{Q}_{\mathrm{L}}>\mathrm{Q}_{\mathrm{H}}$; that is, the low-quality firm produces a higher equilibrium output than the high-quality firm.

In this equilibrium, $\mathrm{P}_{\mathrm{H}}$ is the lowest price that an $\mathrm{H}$-type firm can charge and still deter mimicry by an L-type firm; a higher price also signals high quality, but is less profitable, while a lower price provides a profitable deviation for an L-type firm, if consumers were to infer that the firm that is 
charging that price is an H-type firm. Note that, unlike the full-information equilibrium, wherein a high-quality firm would produce more than a low-quality firm, in the refined asymmetricinformation equilibrium, a low-quality firm produces more output than a high-quality firm: $Q_{L}-Q_{H}$ $>0$. This reflects the distortion in prices due to signaling quality: the high-quality firm's price is so much higher than the price charged by the low-quality firm that consumers are (relatively) redistributed toward the L-type firm.

Some of the results to follow are global, that is, independent of the parameter values (given that they satisfy Assumption 1), while others can be demonstrated via sufficient conditions concerning one or more of the parameters. In particular, a number of our results employ a sufficient condition on the maximum willingness-to-pay, $\alpha$. For convenience, we use the terminology "high value" to denote markets wherein $\alpha$ satisfies a given sufficiency condition (that is, it is "large enough”), which will be made more precise in each result.

Definition 2. A "high-value" market indicates the presence of a finite lower bound for $\alpha$.

Interestingly, a perusal of the formulae (in the Appendix) for $\mathrm{P}_{\mathrm{H}}$ and $\mathrm{P}_{\mathrm{L}}$ reveals that both prices are functions of $\lambda$, the prior probability that a firm is of type H. Thus, unlike separating equilibria in most other models, where only the support of the prior affects the equilibrium, ${ }^{14}$ here the prior probabilities themselves influence the separating equilibrium. As the following proposition

${ }^{14}$ Some exceptions in the literature considering signaling by one firm do exist; see Matthews and Mirman (1983) and Daughety and Reinganum (1995, 2005); see also Daughety and Reinganum (2004) for a duopoly example with a simpler demand structure which yields results similar to Propositions 2 and 3 below. 
indicates, increasing $\lambda$ raises both prices, the gap between the prices, the gap between the quantities, the L-type quantities and profits, and (when dealing with a high-value market) the quantities and profits for the H-type firms.

Proposition 2 (Effect of Prior Probability Distribution on Prices, Quantities and Profits).

(i) An increase in $\lambda$ increases:

1) the equilibrium prices $P_{L}$ and $P_{H}$;

2) the difference between the equilibrium prices $\mathrm{P}_{\mathrm{H}}-\mathrm{P}_{\mathrm{L}}$;

3) the difference between the equilibrium output levels $Q_{L}-Q_{H}$; and

4) the L-type's quantity, $Q_{L}$, and profits, $\Pi_{L}$.

(ii) In high-value markets, an increase in $\lambda$ results in an increase in the H-type's quantity, $\mathrm{Q}_{\mathrm{H}}$, and profits, $\Pi_{\mathrm{H}}$. More formally, $\exists \alpha_{\lambda}<\infty$ such that $\forall \alpha>\alpha_{\lambda}, \lambda \uparrow \Rightarrow \mathrm{Q}_{\mathrm{H}} \uparrow$ and $\Pi_{\mathrm{H}} \uparrow{ }^{15}$

The source of this effect can be understood by reconsidering the definition of equilibrium provided earlier. The incentive compatibility conditions (items (i) and (ii) in the Definition) depend upon the expected price of the competitors, $\mathrm{E}\left(\mathrm{p}^{*}\right)$. Since the equilibrium involves the H-type firm posting a higher price than the L-type firm, an increase in the proportion of firms that are likely to be of type $\mathrm{H}$ shifts the incentive compatibility constraints. Moreover, since firms' prices are strategic complements $(\gamma>0)$, best response functions are upward-sloping, so that an increase in the expected price of a firm's competitors encourages each firm to increase its price.

${ }^{15}$ Note that $\alpha_{\lambda}$ is a function of the parameters of the model. This will be similarly true for other results below, which require a restriction that $\alpha$ be sufficiently large. We use $\alpha$ as the critical variable here because it can be increased without threatening to violate Assumption 1. 
This effect turns out to be parameter-independent for the L-type’s price, quantity and profits, and for the H-type's price; moreover, the difference between the high and low price (and between the low and high quantity) also increases as $\lambda$ increases, again, for all portions of the parameter space. While we cannot provide the same global result for the H-type’s quantity and profit, if the market is high-value, then increasing $\lambda$ also increases the H-type's quantities and profits.

The above results suggest that incomplete information about the quality of the good may act to soften competition; since the firms are choosing prices in a non-cooperative manner, incomplete information may allow them to achieve higher prices. This leads us to the next proposition, which provides a comparison of equilibrium prices under incomplete versus full information. Let $\mathrm{P}^{\mathrm{F}}\left(\theta_{\mathrm{i}}, \theta_{-\mathrm{i}}\right)$ denote the full information price for firm i if its true quality is $\theta_{\mathrm{i}}$ and the vector of its rivals' true qualities is $\theta_{-\mathrm{i}}$; the formula for the full-information price function is provided in the Appendix. Likewise, let $\mathrm{Q}^{\mathrm{F}}\left(\theta_{\mathrm{i}}, \theta_{-\mathrm{i}}\right)$ and $\Pi^{\mathrm{F}}\left(\theta_{\mathrm{i}}, \theta_{-\mathrm{i}}\right)$ denote the corresponding full-information outputs and profits. It is straightforward to show that a firm's full-information price, output and profits are highest when all of its rivals have low-quality products. We will sometimes use the notation $0_{-i}$ to denote an $n$ 1 vector of zeros, and $1_{-i}$ to denote an $n-1$ vector of ones.

Proposition 3 (Prices Under Alternative Information Structures). The equilibrium price under incomplete information is higher, for both firm types, than the corresponding price under full information, regardless of the rivals’ realized qualities; that is, for all $\lambda \in(0,1)$, $\mathrm{P}_{\mathrm{L}}>\mathrm{P}^{\mathrm{F}}\left(0, \theta_{-\mathrm{i}}\right)$ and $\mathrm{P}_{\mathrm{H}}>\mathrm{P}^{\mathrm{F}}\left(1, \theta_{-\mathrm{i}}\right)$ for all $\theta_{-\mathrm{i}}$.

This proposition indicates that there is an upward price distortion for both types of firm, since the 
equilibrium price for each type under incomplete information exceeds the highest price that type of firm would charge (independent of the realizations of the firm's rivals' types) if quality were observable.

Next, the following proposition (also proved in the Appendix) provides a comparison of profits under incomplete information with those under alternative information structures. In particular, we find that an L-type firm always benefits from incomplete information. We obtain a weaker result for an H-type firm by comparing the profits of an H-type firm under incomplete information with a natural analog: the ex ante expected value of an H-type firm's profits under full information (that is, computed just before period 2: the firm knows it is of type $\mathrm{H}$ and takes the expected value of its full-information profits with respect to the rivals’ types).

\section{Proposition 4 (Profits Under Alternative Information Structures).}

(i) The L-type's profits under incomplete information are strictly higher than its fullinformation profits for any realization of the rivals’ types; that is, for all $\lambda \in(0,1), \Pi_{L}>$ $\Pi^{\mathrm{F}}\left(0, \theta_{-\mathrm{i}}\right)$ for all $\theta_{-\mathrm{i}}$.

(ii) As the proportion of H-type firms becomes arbitrarily close to one, the H-type price converges to a value that is higher than the full-information equilibrium price, but (for highvalue markets) lower than the full-information price which would be set by a cartel, in an industry comprised only of H-type firms. More formally, $\lim _{\lambda \rightarrow 1} P_{H}>P^{F}\left(1,1_{-i}\right)$ and

$$
\exists \alpha_{\mathrm{C}}<\infty \text { such that } \forall \alpha>\alpha_{\mathrm{C}}, \lim _{\lambda \rightarrow 1} \mathrm{P}_{\mathrm{H}}<\mathrm{P}_{\mathrm{C}}^{\mathrm{F}} \equiv(\alpha+\mathrm{k}) / 2
$$

Thus, for high-value markets, an H-type firm’s profits under incomplete information exceed the ex ante expected value of an H-type firm's profits under full information when the 
proportion of H-types is sufficiently high.

The fact that H-type firms (at least for some parameter configurations) price below the fullinformation cartel price is yet more significant when one considers the case of a monopolist $(\mathrm{n}=1)$ with private information, which would involve pricing above the full-information monopoly price (due to the signaling distortion). Thus, the presence of competitors moderates the distortionary effects of the presence of incomplete information. Moreover, the proposition implies that there are parameter configurations (high-value markets with a sufficiently high proportion of H-types) for which both types of firm prefer playing an incomplete information game involving product quality to the full-information counterpart. This provides another contrast with the monopoly version of the model, in which an L-type firm would charge its full-information price and obtain its fullinformation profits, while an H-type firm would distort its price upward and necessarily receive lower profits than under full information.

The degree of “competitiveness” and the consumer’s maximum willingness-to-pay also affect the equilibrium, all in an intuitively expected manner, as described in the following proposition.

Proposition 5 (Effects of Product Value, Product Substitutability and the Number of Firms).

(i) An increase in the consumer's willingness-to-pay ( $\alpha$ ) yields an increase in both L-type and H-type equilibrium prices, quantities, and profits, and an increase in the difference in equilibrium prices and the difference in equilibrium quantities; that is,

$$
\alpha \uparrow \Longrightarrow \mathrm{P}_{\mathrm{L}} \uparrow, \mathrm{Q}_{\mathrm{L}} \uparrow, \Pi_{\mathrm{L}} \uparrow, \mathrm{P}_{\mathrm{H}} \uparrow, \mathrm{Q}_{\mathrm{H}} \uparrow, \Pi_{\mathrm{H}} \uparrow, \mathrm{P}_{\mathrm{H}}-\mathrm{P}_{\mathrm{L}} \uparrow \text {, and } \mathrm{Q}_{\mathrm{L}}-\mathrm{Q}_{\mathrm{H}} \uparrow
$$


(ii) In high-value markets, an increase in the degree of product substitutability $(\gamma)$ yields a decrease in both L-type and H-type equilibrium prices, quantities, and profits, and a decrease in the differences both in equilibrium prices and in equilibrium quantities; that is, $\exists \alpha_{\gamma}<\infty$ such that $\forall \alpha>\alpha_{\gamma}, \gamma \uparrow \Rightarrow \mathrm{P}_{\mathrm{L}} \downarrow, \mathrm{Q}_{\mathrm{L}} \downarrow, \Pi_{\mathrm{L}} \downarrow, \mathrm{P}_{\mathrm{H}} \downarrow, \mathrm{Q}_{\mathrm{H}} \downarrow, \Pi_{\mathrm{H}} \downarrow, \mathrm{P}_{\mathrm{H}}-\mathrm{P}_{\mathrm{L}} \downarrow$, and $\mathrm{Q}_{\mathrm{L}}-\mathrm{Q}_{\mathrm{H}} \downarrow$. (iii) In high-value markets, an increase in the number of firms (n) yields a decrease in both L-type and H-type equilibrium prices, quantities, and profits, and a decrease in the differences both in equilibrium prices and in equilibrium quantities; that is, $\exists \alpha_{\mathrm{n}}<\infty$ such that $\forall \alpha>\alpha_{\mathrm{n}}, \mathrm{n} \uparrow \Rightarrow \mathrm{P}_{\mathrm{L}} \downarrow, \mathrm{Q}_{\mathrm{L}} \downarrow, \Pi_{\mathrm{L}} \downarrow, \mathrm{P}_{\mathrm{H}} \downarrow, \mathrm{Q}_{\mathrm{H}} \downarrow, \Pi_{\mathrm{H}} \downarrow, \mathrm{P}_{\mathrm{H}}-\mathrm{P}_{\mathrm{L}} \downarrow$, and $\mathrm{Q}_{\mathrm{L}}-\mathrm{Q}_{\mathrm{H}} \downarrow$.

Thus, higher-value markets have higher prices, greater sales volumes, and higher profits, while increases in competition (brought about either via less product heterogeneity or via the presence of more competitors in the market) reduce prices, sales volumes, and profits when the markets are high-value.

Finally, the loss suffered by a consumer of a low quality product affects the equilibrium, but in a surprising manner. If the loss $(\delta)$ increases, then L-type firms may find it optimal to increase their prices. This is because the increase in the consumer's loss increases the incentive for L-type firms to mimic H-type firms; to deter mimicry, the gap between the prices must increase with any increase in the amount of the loss that consumers of L-type products must bear. This could lead to increased demand for the L-type good, and therefore higher price and profits for the L-type firm. In this event, since the prices are strategic complements, the H-type's price would also rise, though this need not mean that the H-type's quantity or profit would increase. The following proposition characterizes the results of an exogenous increase in the consumer loss parameter, $\delta$. 
Proposition 6 (Effects of Low-Quality Loss).

(i) The difference in prices is always increasing in the loss associated with low quality, $\delta$; that is, $\delta \uparrow \Rightarrow \mathrm{P}_{\mathrm{H}}-\mathrm{P}_{\mathrm{L}} \uparrow$. For high-value markets, the difference in quantities is always increasing in the loss associated with low quality, $\delta$; that is, $\delta \uparrow \Rightarrow \mathrm{Q}_{\mathrm{L}}-\mathrm{Q}_{\mathrm{H}} \uparrow$.

(ii) As the proportion of $\mathrm{H}$-types becomes arbitrarily small, an increase in the loss $\delta$ results in a decrease in the L-type's price, quantity and profits. More formally:

$$
\begin{aligned}
& \lim _{\lambda \rightarrow 0} \partial \mathrm{P}_{\mathrm{L}} / \partial \delta<0 ; \\
& \lim _{\lambda \rightarrow 0} \partial \mathrm{Q}_{\mathrm{L}} / \partial \delta<0 ; \\
& \lim _{\lambda \rightarrow 0} \partial \Pi_{\mathrm{L}} / \partial \delta<0 .
\end{aligned}
$$

(iii) For high-value markets, there are values of the proportion of H-types such that an increase in the loss $\delta$ results in an increase in the L-type's price, quantity and profits, and an increase in the H-type's price as well; that is,

$$
\exists \alpha_{\delta}<\infty \text { and } \lambda_{\delta} \in(0,1) \text { such that } \forall \lambda>\lambda_{\delta}, \delta \uparrow \Rightarrow \mathrm{P}_{\mathrm{L}} \uparrow, \mathrm{Q}_{\mathrm{L}} \uparrow, \Pi_{\mathrm{L}} \uparrow \text {, and } \mathrm{P}_{\mathrm{H}} \uparrow \text {. }
$$

(iv) Alternatively put, for all positive proportions of H-types, in high-value markets an increase in the loss $\delta$ results in an increase in the L-type's price, quantity and profits, and an increase in the H-type's price as well. More formally,

$$
\forall \lambda>0, \exists \alpha_{\delta \lambda}<\infty \text { such that } \forall \alpha>\alpha_{\delta \lambda}, \delta \uparrow \Rightarrow \mathrm{P}_{\mathrm{L}} \uparrow, \mathrm{Q}_{\mathrm{L}} \uparrow, \Pi_{\mathrm{L}} \uparrow \text {, and } \mathrm{P}_{\mathrm{H}} \uparrow
$$

The above proposition paints a surprising picture: for an industry that is comprised of a sufficiently large proportion of $\mathrm{H}$-type firms, an increase in the loss actually can make the L-type 
firms better off. Examples of this are illustrated in Figure 1 below. ${ }^{16}$ The Figure illustrates five

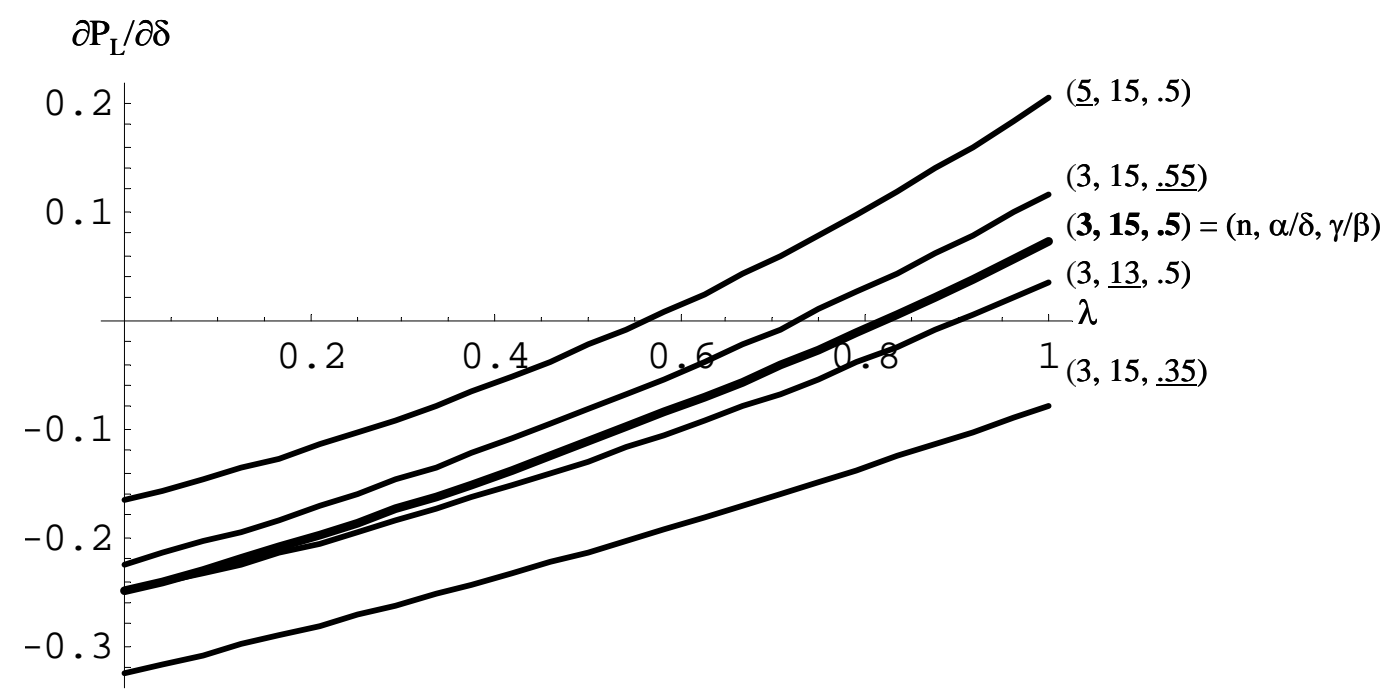

Figure 1. The Effect of an Increase in the Loss on the L-type Price

computations of the curve $\partial \mathrm{P}_{\mathrm{L}} / \partial \delta$, for different values of the relevant parameters (without loss of generality we set $\beta=\delta=1$ ). The heaviest line illustrates the case wherein $n=3, \alpha / \delta=15$ and $\gamma / \beta$ $=0.5$. Variations on this case include increasing $n$, decreasing $\alpha / \delta$ or modifying $\gamma / \beta$; the underlined number in the triple indicates which parameter was changed to obtain the curve. We have included one parameter set, $(n, \alpha / \delta, \gamma / \beta)=(3,15,0.35)$ to illustrate that for some portions of the parameter space, $\partial \mathrm{P}_{\mathrm{L}} / \partial \delta$ is always negative. However, the primary point of the Figure is that there are large portions of the parameter space where, for sufficiently high (but still fractional) values of $\lambda, \partial \mathrm{P}_{\mathrm{L}} / \partial \delta$ is strictly positive. In these portions of the parameter space, $\mathrm{Q}_{\mathrm{L}}$ and $\Pi_{\mathrm{L}}$ increase as well.

We have illustrated this effect in the computations for the Figure for a triopoly, but there are duopoly configurations that also provide this effect. Moreover, as one might conjecture from Proposition 6, higher values of n (consistent with Assumption 1) also produce such curves. Thus,

${ }^{16}$ Of course, only parameter combinations that also satisfied Assumption 1 were considered. 
both smaller and larger industries could satisfy the conditions of the proposition. We again emphasize that this result is due to the interplay between imperfect competition and incomplete information; absent either, we would not see such a result. ${ }^{17}$ In the next section we discuss the implications of this finding in a number of contexts.

\section{Summary of Results}

The Table below summarizes the comparative statics results provided in Propositions 2, 5, and 6. The following notation is used: 1) a global (i.e., parameter-independent) positive sign on a derivative is denoted as $\oplus ; 2$ ) a positive (or negative) sign for a derivative which requires that $\alpha$ be sufficiently large will be denoted as + (or -), while an unknown sign is denoted by a question mark (?); 3) the positive sign for the influence of $\delta$, which is dependent upon both the size of $\alpha$ and of $\lambda$, is denoted $+_{\lambda}$.

${ }^{17}$ In particular, for a monopoly $(n=1)$, it is straightforward to show that $P_{L}, Q_{L}$, and $\Pi_{L}$ are all declining in $\delta$. 
$\underline{\text { Table 1: Comparative Statics Results }}$

\begin{tabular}{|c|c|c|c|c|c|}
\hline & $\alpha$ & $\gamma$ & $\mathrm{n}$ & $\lambda$ & $\delta$ \\
\hline $\mathrm{P}_{\mathrm{L}}$ & $\oplus$ & - & - & $\oplus$ & $+_{\lambda}$ \\
\hline $\mathrm{Q}_{\mathrm{L}}$ & $\oplus$ & - & - & $\oplus$ & $+_{\lambda}$ \\
\hline$\Pi_{\mathrm{L}}$ & $\oplus$ & - & - & $\oplus$ & $+_{\lambda}$ \\
\hline $\mathrm{P}_{\mathrm{H}}$ & $\oplus$ & - & - & $\oplus$ & + \\
\hline $\mathrm{Q}_{\mathrm{H}}$ & $\oplus$ & - & - & + & - \\
\hline$\Pi_{\mathrm{H}}$ & $\oplus$ & - & - & + & $?$ \\
\hline$P_{H}-P_{L}$ & $\oplus$ & - & - & $\oplus$ & $\oplus$ \\
\hline $\mathrm{Q}_{\mathrm{L}}-\mathrm{Q}_{\mathrm{H}}$ & $\oplus$ & - & - & $\oplus$ & + \\
\hline
\end{tabular}

\section{Applications to Tort Reform, Innovation, and Licensing Requirements}

In this section we use the model to address three issues. First, we show that the result concerning an increase in the loss $\delta$ may mean that recent proposals for tort reform may increase (not decrease) lawsuits and amplify the amount of harm consumers may bear. Second, we show why general innovations in the economy, which may provide potential spillovers for specific quality improvements, may not be adopted by the firms in an industry (particularly, those producing lowquality products). Third, we argue that professional licensing regulations that serve to lower the loss due to low quality, $\delta$, may provide a benefit to consumers by increasing competition, thereby reducing prices.

\section{Tort Reform}

The foregoing model suggests that tort reforms currently being suggested, such as "capping” (limiting) damages awards or setting higher evidentiary standards for plaintiffs to win cases, may 
perversely help low-quality firms, possibly at the expense of high-quality producers. To see this, consider the following direct (but algebraically ugly) extension of our model. Assume that the consumer loss, $\delta$, is really comprised of two parts, compensated damages $\left(\delta_{C}\right)$ and uncompensated damages $\left(\delta_{U}\right)$. An example of the former is medical costs for "economic losses" (such as hospitalization costs) and of the latter might be "non-economic losses" (such as emotional distress arising from the harm having occurred), so a cap on recovery of non-economic damages would mean that $\delta_{U}>0$. Such caps have been in operation at the state level, and are currently under consideration in the U.S. Congress. ${ }^{18}$ Damages that are compensated must be paid for by the firm, so this means that the low-quality firm's unit cost of production is now positive: $c_{L}=\delta_{C}$. To maintain the usual incentives for revelation, assume that $\delta_{\mathrm{C}}<\mathrm{c}_{\mathrm{H}}=\mathrm{k}<\delta \equiv \delta_{\mathrm{C}}+\delta_{\mathrm{U}}$. Finally, for simplicity we ignore other losses that might arise due to the filing of lawsuits, settlement bargaining, or trial. ${ }^{19}$

As in the previous section, one can show that (for the modified model) for high-value markets, the L-type's price, quantity and profit are increasing in $\delta_{U}$ for sufficiently high $\lambda$. Thus, the effect of a cap on non-economic damages due to torts arising from products provided in highvalue markets, where there is a sufficiently high proportion of high-quality producers, is to enhance the prospects of the low-quality firms! It is probably not unreasonable to think of medical services

${ }^{18}$ As of this writing, the most recent bill at the federal level is HR 2657, "Comprehensive Medical Malpractice Reform Act of 2005” (introduced May 26, 2005). The first section of the bill, Section 101, provides for limits on recovery of non-economic damages in medical malpractice suits.

19 We also assume a regime of strict liability, so that a firm compensates a victim for "compensable" harms without reference to due care standards. While medical malpractice is technically under a regime of negligence, this difference is not particularly important in what follows, as a low-quality producer is negligent by assumption, while a high-quality producer is never negligent. 
as a high-value market, so such caps may lead to an increased number of malpractice lawsuits, as the price distortion associated with signaling shifts more consumers toward lower-quality medical providers (and more harms). While this discussion formally focuses on caps on damages awards, a simple variation would provide the same result for increases in evidentiary standards (that is, raising the evidentiary requirements that a plaintiff must meet in order to prove a defendant's liability for a tort), as this would increase the expected uncompensated loss.

\section{The Impact of a General Innovation on Specific Product Quality Characteristics}

In the first quarter of the twentieth century, cars rode on wooden wheels with metal rims, undoubtedly as a carry-over from horse-drawn carriages. If not manufactured with a sufficiently high grade of wood (e.g., high-quality hickory), the wood spokes could break, resulting in serious personal injuries. When this happened, customers were usually left to bear the full loss, because products liability law worked to insulate the manufacturer from lawsuits arising down the distribution chain; historically, if the customer had not bought a product directly from the manufacturer, which was certainly true for automobiles and a number of other manufactured products (in the case of automobiles, customers bought cars from dealers), they could not sue for damages. ${ }^{20}$ Improvements in general manufacturing process spelled the death of such wooden wheels when metal vehicle wheels were introduced in $1927 .{ }^{21}$ Thus, a general innovation

${ }^{20}$ MacPherson v. Buick Motor Co., 217 N.Y. 382, is a 1916 case asserting liability by an automobile manufacturer for faultily manufactured wooden vehicle wheels which caused MacPherson's injuries when they disintegrated and caused his car to collapse. This decision, which allowed lawsuits by customers which asserted a manufacturer's negligence, even if they were not direct purchasers, is generally viewed as the watershed in the development of modern products liability law; by 1946 this ruling had become established law (see Keeton, et. al., 1989, pp.16, 52).

${ }^{21}$ See http://www.mutualwheel.com/history.html for the history of a company once in the wooden wheel business. 
(improvements in the manufacturing of specific metal parts for a variety of products) led to a reduction in consumer harms, including those from specific products such as vehicle wheels. ${ }^{22}$

There certainly is reason to expect that this link between general innovation and specific product quality improvements operates in many aspects of economic activity. The model from the previous section suggests that, when conditions are such that $\partial \mathrm{P}_{\mathrm{L}} / \partial \delta>0$, the incentives for lowquality producers (whose products are the source of the loss) to make or adopt such product-specific innovations will be lower than might otherwise have occurred. On the other hand, when $\partial \mathrm{P}_{L} / \partial \delta<$ 0 (for example, in low-value markets without a high proportion of high-quality firms), then the firms potentially creating the loss can benefit from a reduction in $\delta$ brought about by the adoption of an innovation that reduces losses.

\section{Professional Licensing Requirements}

In many industries, especially service industries, producers must meet certain licensing requirements. For instance, real estate brokers, health-care providers, lawyers, accountants, professional engineers, architects, public-school teachers, barbers, and restaurants are typically licensed by the state. One effect of licensing is (arguably) to provide a higher floor on consumer satisfaction with the product (in our model, a smaller value of $\delta$ ) by providing specific training requirements for future practitioners, along with certification examinations. Moreover, meeting the licensing requirement involves a fixed cost, leaving variable costs largely unaffected. In our model, the impact of a licensing requirement that lowers $\delta$, leaving marginal costs unchanged, can have a double benefit to consumers in high-value markets with a sufficiently high proportion of H-type

${ }^{22}$ We are mindful of, but abstracting from, the possibility that safer wheels on cars might result in drivers going at higher speeds (if the car could do this), possibly resulting in more accidents. 
firms. The direct benefit of such a regulation is to reduce the loss due to low quality, but there is also an indirect benefit since both $\mathrm{H}$-type and L-type prices fall, and H-type output increases relative to L-type output. That is, licensing also acts to (relatively) redistribute demand towards high-quality products.

\section{Conclusions}

In this paper, we combine two relatively well-known models from industrial organization and find new and unexpected results. We employ a signaling model in which the quality of a firm's product is its private information; the firm's choice of price may signal its quality to consumers. We integrate this signaling aspect into a model of imperfect competition in a product market with horizontally-differentiated substitute goods. Thus, in choosing its price, a firm must play a best response to its rivals' price strategies and, at the same time, deter mimicry by its own alter ego.

We generate a variety of results that do not occur in the separate portions of the model. For instance, we find that a low-quality firm produces more output than a high-quality firm under incomplete information; this does not occur under full information (though it does occur in a monopoly model with incomplete information).

We find that incomplete information always raises prices for both types of firm. Moreover, there are circumstances under which incomplete information also raises equilibrium profits in the case of imperfect competition, while incomplete information only lowers (or leaves unchanged) equilibrium profits in the case of a monopoly. Under imperfect competition, the need to signal high quality acts as a credible commitment to higher prices, which allows rival firms to price higher as well, and can raise equilibrium profits. Under monopoly, the need to signal high quality causes the 
monopolist to price higher than the full-information monopoly price, thereby reducing profits.

In our model, the parameter representing the proportion of high-quality firms is an important determinant of equilibrium prices, quantities and profits, all of which are increasing in this parameter. A higher proportion of high-quality rivals implies a higher expected rival price and, since prices are strategic complements, a higher own price. At the same time, a higher expected rival price shifts demand toward the firm so that it also produces a higher quantity of output. Combining these two effects clearly implies higher profits. This parameter does not matter in a monopoly version of the model, nor in the full-information version of the model.

We find that (for some parameter values) an increase in the loss associated with low quality can have the perverse effect of increasing the price, quantity and profits of a low-quality firm. A higher loss increases the incentive for a low-quality firm to mimic a high-quality firm, causing the high-quality firm to raise its price even further to signal its quality. This in turn allows the lowquality firm to increase its price (due to strategic complementarity) and shifts demand toward the low-quality firm. This cannot occur in a monopoly version of the model with incomplete information, nor can it occur in a full-information model.

It is reassuring that some cherished results do carry over in this model (at least for high-value markets). In particular, the incomplete-information imperfect-competition model behaves as expected with respect to the variables that measure market size, product substitutability and the number of firms. A higher-value market corresponds to higher prices, outputs and profits for both quality levels, while an increase in the substitutability of the products or an increase in the number of firms causes prices, output (per firm) and profits to fall.

We employ the model to address three applications. In the case of tort reform, our results 
on the effect of the increase in the consumer loss on low-quality firm prices, quantities and profits suggest that such reforms as caps on damages or increased evidentiary standards may backfire, possibly leading to higher losses and more lawsuits. In the case of general innovations and spillovers to improving the quality of specific products, we find that low-quality firms may have reduced incentives to apply such innovations. Finally, we find that professional licensing requirements may actually enhance competitiveness and lead to reduced prices, in addition to their straightforward effect on consumer satisfaction. 
Appendix

\section{Derivation of the Symmetric Separating Equilibrium Price Function}

Derivation of Best Response Functions

Recall the function describing firm i's profit as a function of its price, $\mathrm{p}_{\mathrm{i}}$, its actual type, $\theta_{\mathrm{i}}$, and the type the consumer believes it to be, $\widetilde{\theta}$ :

$$
\Pi_{\mathrm{i}}\left(\mathrm{p}_{\mathrm{i}}, \theta_{\mathrm{i}}, \widetilde{\theta}_{\mathrm{i}} \mid \mathrm{E}\left(\mathrm{p}^{*}\right)\right) \equiv\left(\mathrm{p}_{\mathrm{i}}-\mathrm{k} \theta_{\mathrm{i}}\right)\left(\mathrm{a}-\mathrm{b}\left(1-\widetilde{\theta}_{\mathrm{i}}\right) \delta+\mathrm{g}(\mathrm{n}-1)(1-\lambda) \delta-\mathrm{b} \mathrm{p}_{\mathrm{i}}+\mathrm{g}(\mathrm{n}-1) \mathrm{E}\left(\mathrm{p}^{*}\right)\right) .
$$

Note that for any given price, it is always more profitable to be perceived as type $\mathrm{H}$, regardless of true type; and for any given price, it is better to be type $\mathrm{L}$, regardless of perceived type. If there were no signaling considerations, then $\Pi_{\mathrm{st}} \equiv\left(\mathrm{p}-\mathrm{c}_{\mathrm{s}}\right) \mathrm{b}\left(\mathrm{d}_{\mathrm{t}}-\mathrm{p}\right)$ would be maximized by $\rho_{\mathrm{st}}=\left(\mathrm{c}_{\mathrm{s}}+\mathrm{d}_{\mathrm{t}}\right) / 2$, and the resulting profits would be $\Pi_{s t}=b\left(d_{t}-c_{s}\right)^{2} / 4$. These prices (actually, "best responses" to $\mathrm{E}\left(\mathrm{p}^{*}\right)$ ) are ordered as follows: $\rho_{\mathrm{HH}}>\rho_{\mathrm{LH}}>\rho_{\mathrm{HL}}>\rho_{\mathrm{LL}}$. The only non-obvious case is $\rho_{\mathrm{LH}}>\rho_{\mathrm{HL}}$; this holds if and only if $\mathrm{d}_{\mathrm{H}}-\mathrm{d}_{\mathrm{L}}>\mathrm{C}_{\mathrm{H}}-\mathrm{C}_{\mathrm{L}}$, which is ensured by the assumption that $\delta>\mathrm{k}$.

Our method of deriving the separating equilibrium prices is to first derive a best response function for firm i that reflects the need to signal its type. This will consist of a pair of prices $\left(\rho_{\mathrm{L}}\left(\mathrm{E}\left(\mathrm{p}^{*}\right)\right), \rho_{\mathrm{H}}\left(\mathrm{E}\left(\mathrm{p}^{*}\right)\right)\right)$. We will then impose the equilibrium condition that $\mathrm{E}\left(\mathrm{p}^{*}\right)=\lambda \rho_{\mathrm{H}}\left(\mathrm{E}\left(\mathrm{p}^{*}\right)\right)+$ $(1-\lambda) \rho_{\mathrm{L}}\left(\mathrm{E}\left(\mathrm{p}^{*}\right)\right)$ and solve for a fixed point. Finally, the resulting solution is substituted into $\left(\rho_{\mathrm{L}}\left(\mathrm{E}\left(\mathrm{p}^{*}\right)\right), \rho_{\mathrm{H}}\left(\mathrm{E}\left(\mathrm{p}^{*}\right)\right)\right)$ to obtain the equilibrium interim prices.

No firm is willing to distort its price away from its best response (were its type known) in order to be perceived as type $\mathrm{L}$ (since this is the worst type to be perceived to be). Thus, if a firm of type $L$ is perceived as such, its best response is $\rho_{L L}$, which yields profits of $b\left(d_{L}-c_{L}\right)^{2} / 4$. If a firm of type $H$ is perceived as being of type $L$, its best response is $\rho_{H L}$, which yields profits of $b\left(d_{L}\right.$ $\left.\mathrm{C}_{\mathrm{H}}\right)^{2} / 4$.

However, either firm would be willing to distort its price away from its best response (were its type known) in order to be perceived as type $\mathrm{H}$. Thus, a candidate for a revealing equilibrium must involve a best response for type $\mathrm{H}$ that satisfies two conditions. First, it must deter mimicry by the type $\mathrm{L}$ firm (who thus reverts to $\rho_{\mathrm{LL}}$ ); and second, it must be worthwhile for the type $\mathrm{H}$ firm to use this price rather than to allow itself to be perceived as a type L firm (and thus revert to $\rho_{\mathrm{HL}}$ ). Formally, a separating best response for the type $\mathrm{H}$ firm is a member of the following set:

$$
\left\{p \mid\left(p-c_{L}\right) b\left(d_{H}-p\right) \leq b\left(d_{L}-c_{L}\right)^{2} / 4 \text { and }\left(p-c_{H}\right) b\left(d_{H}-p\right) \geq b\left(d_{L}-c_{H}\right)^{2} / 4\right\} \text {. }
$$

The first inequality says that the type $L$ firm prefers to price at $\rho_{\mathrm{LL}}$ (and be perceived as type $\mathrm{L}$ ) than to price at $\mathrm{p}$ (and be perceived as type $\mathrm{H}$ ). The second inequality says that the type $\mathrm{H}$ firm prefers to price at $\mathrm{p}$ (and be perceived as type $\mathrm{H}$ ) than to price at $\rho_{\mathrm{HL}}$ (and be perceived as type $\mathrm{L}$ ). Solving these two inequalities implies that the H-type firm's best response belongs to the interval:

$$
\left[.5\left\{d_{H}+c_{L}+\left(\left(d_{H}-c_{L}\right)^{2}-\left(d_{L}-c_{L}\right)^{2}\right)^{1 / 2}\right\}, .5\left\{d_{H}+c_{H}+\left(\left(d_{H}-c_{H}\right)^{2}-\left(d_{L}-c_{H}\right)^{2}\right)^{1 / 2}\right\}\right] .
$$


This entire interval involves prices in excess of $\rho_{\mathrm{HH}}=\left(\mathrm{d}_{\mathrm{H}}+\mathrm{C}_{\mathrm{H}}\right) / 2$; thus, the type $\mathrm{H}$ firm distorts its price upwards from the best response function it would follow if it were known to be of type $\mathrm{H}^{23}$

\section{Refinement of Best Response Functions}

We have identified an interval of candidates for the type $\mathrm{H}$ firm's best response. We now apply the Intuitive Criterion (see Mas-Colell, Whinston and Green, 1995, pp. 470-471, for a discussion of equilibrium domination and the Intuitive Criterion of Cho and Kreps, 1987). It is appropriate to apply this refinement at this stage in the game because, conditional on any common conjecture (common to firm i and consumers) about the strategy being employed by all other firms (including the equilibrium strategy), what remains is simply a signaling game between firm i's two types and consumers. The Intuitive Criterion says that consumers should infer type $\mathrm{H}$ from firm i's price $\mathrm{p}$ so long as type $\mathrm{H}$ would be willing to charge $\mathrm{p}$, yet mimicry by type $\mathrm{L}$ would be deterred, even under this most-favorable inference. Thus, the firm of type $\mathrm{H}$ distorts its best response to the minimum extent necessary to deter mimicry by its alter ego (type $\mathrm{L}$ ). Formally, this means that firm i can convince consumers that it is of type $\mathrm{H}$ by playing the separating best response $\rho_{\mathrm{H}}\left(\mathrm{E}\left(\mathrm{p}^{*}\right)\right)=$ $.5\left\{\mathrm{~d}_{\mathrm{H}}+\mathrm{C}_{\mathrm{L}}+\left(\left(\mathrm{d}_{\mathrm{H}}-\mathrm{C}_{\mathrm{L}}\right)^{2}-\left(\mathrm{d}_{\mathrm{L}}-\mathrm{c}_{\mathrm{L}}\right)^{2}\right)^{1 / 2}\right\}$. As argued above, type L's best response is $\rho_{\mathrm{L}}\left(\mathrm{E}\left(\mathrm{p}^{*}\right)\right)=\left(\mathrm{d}_{\mathrm{L}}\right.$ $\left.+c_{L}\right) / 2$. Note that $E\left(p^{*}\right)$ enters these functions through the terms $d_{H}$ and $d_{L}$. Recalling that $c_{L}=0$, we can simplify to obtain: $\rho_{\mathrm{H}}\left(\mathrm{E}\left(\mathrm{p}^{*}\right)\right)=.5\left\{\mathrm{~d}_{\mathrm{H}}+\left(\left(\mathrm{d}_{\mathrm{H}}-\mathrm{d}_{\mathrm{L}}\right)\left(\mathrm{d}_{\mathrm{H}}+\mathrm{d}_{\mathrm{L}}\right)\right)^{1 / 2}\right\}$ and $\rho_{\mathrm{L}}\left(\mathrm{E}\left(\mathrm{p}^{*}\right)\right)=\mathrm{d}_{\mathrm{L}} / 2$.

\section{Derivation of Refined Equilibrium Prices}

Each type of firm i plays a best response to the common rival separating strategy (which is summarized, for firm i's purposes, by its expected value). Then in a symmetric equilibrium, the equilibrium expected price, $\mathrm{E}\left(\mathrm{p}^{*}\right)$, is a solution to the equation:

$$
\mathrm{X}=\lambda \rho_{\mathrm{H}}(\mathrm{X})+(1-\lambda) \rho_{\mathrm{L}}(\mathrm{X})=\lambda \mathrm{d}_{\mathrm{H}} / 2+(1-\lambda) \mathrm{d}_{\mathrm{L}} / 2+(\lambda / 2)\left(\left(\mathrm{d}_{\mathrm{H}}-\mathrm{d}_{\mathrm{L}}\right)\left(\mathrm{d}_{\mathrm{H}}+\mathrm{d}_{\mathrm{L}}\right)\right)^{1 / 2} .
$$

Upon substitution, we obtain:

$$
\mathrm{X}=[\mathrm{U}+\mathrm{g}(\mathrm{n}-1) \mathrm{X}] / 2 \mathrm{~b}+\lambda \delta / 2+\lambda\left\{\delta[(\mathrm{U}+\mathrm{g}(\mathrm{n}-1) \mathrm{X}) / 2 \mathrm{~b}]+\delta^{2} / 4\right\}^{1 / 2},
$$

where $\mathrm{U} \equiv \mathrm{a}-\mathrm{b} \delta+\mathrm{g}(\mathrm{n}-1)(1-\lambda) \delta>0$ by Assumption 1 . Let $\mathrm{Y} \equiv[\mathrm{U}+\mathrm{g}(\mathrm{n}-1) \mathrm{X}] / 2 \mathrm{~b}$; then $\mathrm{X}=(2 \mathrm{bY}$ - U)/g(n-1), and (A2) becomes:

$$
\mathrm{Y}[2 \mathrm{~b}-\mathrm{g}(\mathrm{n}-1)] / \mathrm{g}(\mathrm{n}-1)=\mathrm{U} / \mathrm{g}(\mathrm{n}-1)+\lambda \delta / 2+\lambda\{\delta(\mathrm{Y}+\delta / 4)\}^{1 / 2} .
$$

For later purposes, note that $\rho_{\mathrm{L}}\left(\mathrm{E}\left(\mathrm{p}^{*}\right)\right)=\mathrm{d}_{\mathrm{L}} / 2=\mathrm{Y}$.

Finally, let $\mathrm{W} \equiv\{\delta(\mathrm{Y}+\delta / 4)\}^{1 / 2}$; then $\mathrm{Y}=\mathrm{W}^{2} / \delta$ - $\delta / 4$. For later purposes, note that $\rho_{\mathrm{H}}\left(\mathrm{E}\left(\mathrm{p}^{*}\right)\right)$ $=\mathrm{d}_{\mathrm{H}} / 2+\mathrm{W}$ and $\rho_{\mathrm{H}}\left(\mathrm{E}\left(\mathrm{p}^{*}\right)\right)-\rho_{\mathrm{L}}\left(\mathrm{E}\left(\mathrm{p}^{*}\right)\right)=\mathrm{d}_{\mathrm{H}} / 2+\mathrm{W}-\mathrm{d}_{\mathrm{L}} / 2=\delta / 2+\mathrm{W}$. Substitution of Yin terms of $\mathrm{W}$

${ }^{23}$ The type $\mathrm{H}$ firm could also deter mimicry by the type L firm by using a downwarddistorted price but type $\mathrm{H}$ would prefer to give up and be taken as a type $\mathrm{L}$ firm rather than use such a low price to distinguish itself. 
into (A3) and simplification yields the following quadratic in W:

$$
\eta_{1} \mathrm{~W}^{2}+\eta_{2} \mathrm{~W}+\eta_{3}=0
$$

where $\eta_{1}=[2 \mathrm{~b}-(\mathrm{n}-1) \mathrm{g}] / \delta, \eta_{2}=-\lambda \mathrm{g}(\mathrm{n}-1)$ and $\eta_{3}=-\mathrm{U}-\lambda \mathrm{g}(\mathrm{n}-1) \delta / 2-(\delta / 4)[2 \mathrm{~b}-(\mathrm{n}-1) \mathrm{g}]$. The coefficient $\eta_{1}$ is positive, while $\eta_{2}$ and $\eta_{3}$ are negative. Thus, equation (A4) has one positive and one negative root; given than $\mathrm{W}$ is defined as a square root, the solution we seek is the positive root of equation (A4). Solving and substituting back the original parameters, $\mathrm{W}^{*}$ can be written as:

$$
\mathrm{W}^{*}=\left[\lambda \delta \gamma(\mathrm{n}-1)+\left\{(\lambda \delta \gamma(\mathrm{n}-1))^{2}+4 \delta(2 \beta+(\mathrm{n}-3) \gamma) \eta_{4}\right\}^{.5}\right] / 2(2 \beta+(\mathrm{n}-3) \gamma),
$$

where $\eta_{4} \equiv \alpha(\beta-\gamma)-\delta(\beta+(n-2) \gamma)+\gamma \delta(n-1)(1-\lambda)+\lambda \delta \gamma(n-1) / 2+(\delta / 4)(2 \beta+(n-3) \gamma)$. Using the fact that $\mathrm{W}=\{\delta(\mathrm{Y}+\delta / 4)\}^{1 / 2}$ and (A3), we can obtain:

$$
\mathrm{Y}^{*}=\left[\mathrm{U}+\lambda \delta \mathrm{g}(\mathrm{n}-1) / 2+\lambda \mathrm{g}(\mathrm{n}-1) \mathrm{W}^{*}\right] /[2 \mathrm{~b}-(\mathrm{n}-1) \mathrm{g}] .
$$

Finally, using the fact that $X=(2 b Y-U) / g(n-1)$, we obtain $X^{*}=\left[U+b \lambda \delta+2 b \lambda W^{*}\right] /[2 b-(n-1) g]$.

We noted above that $\rho_{\mathrm{L}}\left(\mathrm{E}\left(\mathrm{p}^{*}\right)\right)=\mathrm{Y}$ and $\rho_{\mathrm{H}}\left(\mathrm{E}\left(\mathrm{p}^{*}\right)\right)-\rho_{\mathrm{L}}\left(\mathrm{E}\left(\mathrm{p}^{*}\right)\right)=\delta / 2+\mathrm{W}$. Thus the equilibrium interim prices $\mathrm{P}_{\mathrm{L}}$ and $\mathrm{P}_{\mathrm{H}}$ are simply $\mathrm{P}_{\mathrm{L}}=\rho_{\mathrm{L}}\left(\mathrm{X}^{*}\right)=\mathrm{Y}^{*}$ and $\mathrm{P}_{\mathrm{H}}=\rho_{\mathrm{H}}\left(\mathrm{X}^{*}\right)=\mathrm{Y}^{*}+\delta / 2+$ $\mathrm{W}^{*}$. The equilibrium interim quantities are $\mathrm{Q}_{\mathrm{L}}=\mathrm{bY}^{*}$ and $\mathrm{Q}_{\mathrm{H}}=\mathrm{b}\left(\mathrm{Y}^{*}+\delta / 2-\mathrm{W}^{*}\right)$. Finally, the equilibrium interim profits are $\Pi_{\mathrm{L}}=\mathrm{b}\left(\mathrm{Y}^{*}\right)^{2}$ and $\Pi_{\mathrm{H}}=\left(\mathrm{Y}^{*}+\delta / 2+\mathrm{W}^{*}-\mathrm{k}\right) \mathrm{b}\left(\mathrm{Y}^{*}+\delta / 2-\mathrm{W}^{*}\right)$.

\section{Results and Proofs of Selected Propositions}

Proof of Proposition 1. We have identified a unique (refined) candidate for a symmetric separating equilibrium. To verify that the strategies and beliefs do provide a separating equilibrium, suppose that all firms but firm i play the strategy $\left(\mathrm{P}_{\mathrm{L}}, \mathrm{P}_{\mathrm{H}}\right)$ given above, with expected value $\mathrm{X}^{*}$, and that consumers maintain the beliefs: $\mathrm{B}^{*}(\mathrm{p})=0$ when $\mathrm{p}<\mathrm{P}_{\mathrm{H}}$, and $\mathrm{B}^{*}(\mathrm{p})=1$ when $\mathrm{p} \geq \mathrm{P}_{\mathrm{H}}$. Then, by construction, the type $L$ firm i would be unwilling to charge a price at or above $\mathrm{P}_{\mathrm{H}}$ (which is equal to $\rho_{\mathrm{H}}\left(\mathrm{X}^{*}\right)$ ) in order to be taken for type $\mathrm{H}$. Rather, it will prefer to be taken for type $\mathrm{L}$ and to charge the price $\mathrm{P}_{\mathrm{L}}$ (which is equal to $\rho_{\mathrm{L}}\left(\mathrm{X}^{*}\right)$ ). On the other hand, the type $\mathrm{H}$ firm $\mathrm{i}$ would be willing to charge a price at or somewhat above $\mathrm{P}_{\mathrm{H}}$ (which is equal to $\rho_{\mathrm{H}}\left(X^{*}\right)$ ) in order to be taken for type $\mathrm{H}$, but among these it prefers the lowest price; that is, $\mathrm{P}_{\mathrm{H}}$. The consumer's beliefs are correct in equilibrium, and $\mathrm{X}^{*}=\lambda \mathrm{P}_{\mathrm{H}}+(1-\lambda) \mathrm{P}_{\mathrm{L}}$. Finally, note that $\mathrm{P}_{\mathrm{H}}-\mathrm{P}_{\mathrm{L}}=\delta / 2+\mathrm{W}^{*}>0$, and $\mathrm{Q}_{\mathrm{L}}-\mathrm{Q}_{\mathrm{H}}=$ $b\left(W^{*}-\delta / 2\right)$, which is easily shown to be positive. QED.

Elimination of (Pure) Pooling Equilibria

Consider possible pooling equilibria. Firms will pool at a price $\mathrm{P}^{\mathrm{P}}$ if the following incentive compatibility constraints hold:

$$
\text { i) } \Pi_{i}\left(\mathrm{P}^{\mathrm{P}}, 0, \lambda \mid \mathrm{P}^{\mathrm{P}}\right) \geq \max _{\mathrm{p}} \Pi_{\mathrm{i}}\left(\mathrm{p}, 0,0 \mid \mathrm{P}^{\mathrm{P}}\right) \text { and } \text { ii) } \Pi_{\mathrm{i}}\left(\mathrm{P}^{\mathrm{P}}, 1, \lambda \mid \mathrm{P}^{\mathrm{P}}\right) \geq \max _{\mathrm{p}} \Pi_{\mathrm{i}}\left(\mathrm{p}, 1,0 \mid \mathrm{P}^{\mathrm{P}}\right) \text {, }
$$

with beliefs $\mathrm{B}(\mathrm{P})=0$ for $\mathrm{P} \neq \mathrm{P}^{\mathrm{P}}$. The above incentive constraints express the profits of firm $\mathrm{i}$ at the 
pooling price, when consumers believe it is an $\mathrm{H}$-type firm with probability $\lambda$, supported by beliefs that treat any out-of-equilibrium price as indicating that the firm is L-type for sure. The pair of inequalities in (A7) generate the following associated inequalities in terms of the parameters of the problem:

$$
\text { i) } \mathrm{P}^{\mathrm{P}} \mathrm{b}\left(\mathrm{d}^{\mathrm{P}}-\mathrm{P}^{\mathrm{P}}\right) \geq \mathrm{b}\left(\mathrm{d}_{\mathrm{L}} / 2\right)^{2} \text { and ii) }\left(\mathrm{P}^{\mathrm{P}}-\mathrm{k}\right) \mathrm{b}\left(\mathrm{d}^{\mathrm{P}}-\mathrm{P}^{\mathrm{P}}\right) \geq \mathrm{b}\left(\left(\mathrm{d}_{\mathrm{L}}-\mathrm{k}\right) / 2\right)^{2} \text {, }
$$

where $d^{P}$ is the "pooled" version of $d_{H}$ and $d_{L}$, and can be shown to be $d^{P}=d_{L}+\lambda \delta$.

We need not actually construct a pooling equilibrium, as we need only show that if one exists, then there is a price to which the H-type firm could profitably defect (that would be unprofitable for an L-type firm) if consumers were to update their beliefs and infer that the signal came from an $\mathrm{H}$-type firm. Thus, $\mathrm{P}^{\mathrm{P}}$ fails the Intuitive Criterion if there exists $\mathrm{P}^{*}$ such that:

$$
\text { i) } \left.\mathrm{P}^{*} \mathrm{~b}\left(\mathrm{~d}_{\mathrm{H}}-\mathrm{P}^{*}\right) \leq \mathrm{P}^{\mathrm{P}} \mathrm{b}\left(\mathrm{d}^{\mathrm{P}}-\mathrm{P}^{\mathrm{P}}\right) \text { and } \mathrm{ii}\right)\left(\mathrm{P}^{*}-\mathrm{k}\right) \mathrm{b}\left(\mathrm{d}_{\mathrm{H}}-\mathrm{P}^{*}\right) \geq\left(\mathrm{P}^{\mathrm{P}}-\mathrm{k}\right) \mathrm{b}\left(\mathrm{d}^{\mathrm{P}}-\mathrm{P}^{\mathrm{P}}\right) \text {. }
$$

In (A8) the left-hand-side of each inequality are the profits that would be obtained by (respectively) the L-type and H-type firms by defecting (and being taken to be an H-type firm after consumers have updated their beliefs), while the profits from the pooling equilibrium appear on the right-handside.

Let us denote the roots to (A8i) as $\mathrm{P}_{\mathrm{L}}^{-}$and $\mathrm{P}_{\mathrm{L}}^{+}>\mathrm{P}_{\mathrm{L}}^{-}$, and the roots to (A8ii) as $\mathrm{P}_{\mathrm{H}}^{-}$and $\mathrm{P}_{\mathrm{H}}^{+}>\mathrm{P}_{\mathrm{H}}^{-}$. Then (A8) is equivalent to asking if there exists $\mathrm{P}^{*}$ such that $\mathrm{P}^{*} \in\left[\mathrm{P}_{\mathrm{H}}^{-}, \mathrm{P}_{\mathrm{H}}^{+}\right]$and $\mathrm{P}^{*} \notin\left[\mathrm{P}_{\mathrm{L}}^{-}, \mathrm{P}_{\mathrm{L}}^{+}\right]$; if so, then $\mathrm{P}^{\mathrm{P}}$ fails the Intuitive Criterion. With a little algebra one can show that $\mathrm{P}_{\mathrm{H}}^{+}>\mathrm{P}_{\mathrm{L}}^{+}$, so such a $\mathrm{P}^{*}$ exists for any $\mathrm{P}^{\mathrm{P}}$. Thus no pooling equilibrium survives refinement.

\section{Full-Information Price and Profit Formula}

Let firm i's type be $\theta_{\mathrm{i}}$ and firm i's rivals' types be summarized by the vector of types $\theta_{-\mathrm{i}}$. Then the full-information equilibrium price for firm i is:

$$
\begin{aligned}
\mathrm{P}^{\mathrm{F}}\left(\theta_{\mathrm{i}}, \theta_{-\mathrm{i}}\right)=\left[\mathrm{a}-(\mathrm{b}-(\mathrm{n}-1) \mathrm{g}) \delta+\mathrm{b}(\mathrm{k}+\delta) \theta_{\mathrm{i}}-\mathrm{g} \delta \sum_{\mathrm{j \neq i}} \theta_{\mathrm{j}}\right. \\
\left.+\mathrm{g}\left\{\mathrm{n}[\mathrm{a}-(\mathrm{b}-(\mathrm{n}-1) \mathrm{g}) \delta]+[(\mathrm{b}-(\mathrm{n}-1) \mathrm{g}) \delta+\mathrm{bk}] \sum_{\mathrm{j}} \theta_{\mathrm{j}}\right\} /(2 \mathrm{~b}-(\mathrm{n}-1) \mathrm{g})\right] /(2 \mathrm{~b}+\mathrm{g}) .
\end{aligned}
$$

The full-information price for an industry comprised only of L-type firms is $\mathrm{P}_{\mathrm{L}}^{\mathrm{F}} \equiv \mathrm{P}^{\mathrm{F}}\left(0,0_{-i}\right)$ and the full-information price for an industry comprised only of $\mathrm{H}$-type firms is $\mathrm{P}_{\mathrm{H}}^{\mathrm{F}} \equiv \mathrm{P}^{\mathrm{F}}\left(1,1_{-\mathrm{i}}\right)$, where $0_{-i}$ denotes an $n-1$ vector of 0 s and $1_{-i}$ denotes an $n-1$ vector of 1 s. Finally, substitution and simplification yields $\Pi^{\mathrm{F}}\left(0, \theta_{-\mathrm{i}}\right)=\mathrm{b}\left(\mathrm{P}^{\mathrm{F}}\left(0, \theta_{-\mathrm{i}}\right)\right)^{2}$ and $\Pi^{\mathrm{F}}\left(1, \theta_{-\mathrm{i}}\right)=\mathrm{b}\left(\mathrm{P}^{\mathrm{F}}\left(1, \theta_{-\mathrm{i}}\right)-\mathrm{k}\right)^{2}$.

Proof of Proposition 3. In each argument below, the first inequality follows from Proposition 2, and the remaining results follow from evaluating and comparing the pricing equations. First consider the L-type firm: for all $\lambda \in(0,1), \mathrm{P}_{\mathrm{L}}>\lim _{\lambda \rightarrow 0} \mathrm{P}_{\mathrm{L}}=(\alpha-\delta)(\beta-\gamma) /[2 \beta+(\mathrm{n}-3) \gamma]=\mathrm{P}^{\mathrm{F}}\left(0,0_{-\mathrm{i}}\right) \geq$ $\mathrm{P}^{\mathrm{F}}\left(0, \theta_{-\mathrm{i}}\right)$ for all $\theta_{-\mathrm{i}}$. Now consider the H-type firm: for all $\lambda \in(0,1), \mathrm{P}_{\mathrm{H}}>\lim _{\lambda \rightarrow 0} \mathrm{P}_{\mathrm{H}}>(\alpha-\delta)(\beta-$ $\gamma) /[2 \beta+(n-3) \gamma]+\delta>P^{F}\left(1,0_{-i}\right) \geq P^{F}\left(1, \theta_{-i}\right)$ for all $\theta_{-i}$. QED. 
Proof of Proposition 4. (i) $\Pi_{\mathrm{L}}=\mathrm{b}\left(\mathrm{P}_{\mathrm{L}}\right)^{2}$ and $\Pi^{\mathrm{F}}\left(0, \theta_{-\mathrm{i}}\right)=\mathrm{b}\left(\mathrm{P}^{\mathrm{F}}\left(0, \theta_{-\mathrm{i}}\right)\right)^{2}$, so the claim follows immediately from Proposition 3. (ii) Note that $\lim _{\lambda \rightarrow 1} \mathrm{P}_{\mathrm{H}}=\left[\alpha(\beta-\gamma)+2(\beta+(\mathrm{n}-2) \gamma) \mathrm{W}^{*}\right] /[2 \beta+$ $(\mathrm{n}-3) \gamma]$, while $\mathrm{P}^{\mathrm{F}}\left(1,1_{-\mathrm{j}}\right)=[\alpha(\beta-\gamma)+\mathrm{k}(\beta+(\mathrm{n}-2) \gamma)] /[2 \beta+(\mathrm{n}-3) \gamma]$. Thus, $\lim _{\lambda \rightarrow 1} \mathrm{P}_{\mathrm{H}}>\mathrm{P}^{\mathrm{F}}\left(1,1_{-\mathrm{i}}\right)$ if and only if $2 \mathrm{~W}^{*}>\mathrm{k}$, which is easily verified. The full-information price for a collusive industry comprised only of H-type firms is $\mathrm{P}_{\mathrm{C}}^{\mathrm{F}}=(\alpha+\mathrm{k}) / 2$. Then $\lim _{\lambda \rightarrow 1} \mathrm{P}_{\mathrm{H}}<(\alpha+\mathrm{k}) / 2$ if and only if $\alpha(\mathrm{n}$ 1) $\gamma+k(2 \beta+(n-3) \gamma)>4 W^{*}(\beta+(n-2) \gamma)$. This is certainly true if $\alpha$ is large enough, since the lefthand-side is increasing linearly in $\alpha$, while the right-hand-side increases with the square root of $\alpha$. When $\lim _{\lambda \rightarrow 1} P_{H}$ is less than the collusive price, then we can conclude that $\lim _{\lambda \rightarrow 1} \Pi_{H}>\Pi^{F}\left(1,1_{-i}\right)$. This is because, when all firms charge the same price (whether it is the noncooperative fullinformation price, the collusive full-information price, or the interim price), each firm's profits are given by $(p-k)(a-(b-(n-1) g) p)$, which is a quadratic function that reaches its maximum at the collusive price. Thus, for high-value markets, $\lim _{\lambda \rightarrow 1} \Pi_{\mathrm{H}}>\Pi^{\mathrm{F}}\left(1,1_{-\mathrm{i}}\right)=\lim _{\lambda \rightarrow 1} \mathrm{E}_{-\mathrm{i}}\left\{\Pi^{\mathrm{F}}\left(1, \theta_{-\mathrm{i}}\right)\right\}$, where the equality follows since in the limit only the term $\Pi^{\mathrm{F}}\left(1,1_{-\mathrm{i}}\right)$ has positive weight. Consequently, $\Pi_{\mathrm{H}}>\mathrm{E}_{-\mathrm{i}}\left\{\Pi^{\mathrm{F}}\left(1, \theta_{-\mathrm{i}}\right)\right\}$ when $\lambda$ is sufficiently close to 1 . QED.

Example of Computation for Proposition 6. Recall that $\mathrm{P}_{\mathrm{L}}=\mathrm{Y}^{*}$ from equation (A6) and $\mathrm{P}_{\mathrm{H}}=\mathrm{Y}^{*}$ $+\delta / 2+W^{*}$ from equation (A5). First consider the effect of $\delta$ on $W^{*}$.

$$
\begin{aligned}
& \operatorname{sgn}\left\{\partial \mathrm{W}^{*} / \partial \delta\right\}=\operatorname{sgn}\{\lambda \gamma(\mathrm{n}-1) \\
& \left.+.5\left[2 \delta(\lambda \gamma(\mathrm{n}-1))^{2}+4(2 \beta+(\mathrm{n}-3) \gamma)\left(\partial\left(\delta \eta_{4}\right) / \partial \delta\right)\right] /\left[(\lambda \delta \gamma(\mathrm{n}-1))^{2}+4 \delta(2 \beta+(\mathrm{n}-3) \gamma) \eta_{4}\right]^{.5}\right\}
\end{aligned}
$$

Note that $\partial \mathrm{W}^{*} / \partial \delta>0$ for all $\lambda \in[0,1]$ if $\partial\left(\delta \eta_{4}\right) / \partial \delta>0$ for all $\lambda \in[0,1]$. But

$$
\begin{aligned}
\partial\left(\delta \eta_{4}\right) / \partial \delta=\alpha & (\beta-\gamma)-2 \delta(\beta+(\mathrm{n}-2) \gamma) \\
& +2 \gamma \delta(\mathrm{n}-1)(1-\lambda)+2 \lambda \delta \gamma(\mathrm{n}-1) / 2+2(\delta / 4)(2 \beta+(\mathrm{n}-3) \gamma) .
\end{aligned}
$$

The first line is positive by Assumption 1, and the remaining terms are non-negative for all $\lambda$. Thus, we conclude that $\partial \mathrm{W}^{*} / \partial \delta>0$ for all $\lambda \in[0,1]$. This implies that $\mathrm{P}_{\mathrm{H}}-\mathrm{P}_{\mathrm{L}}=\delta / 2+\mathrm{W}^{*}$ is strictly increasing in $\delta$ for all $\lambda \in[0,1]$.

Now consider the effect of $\delta$ on $\mathrm{Y}^{*}$.

$$
\operatorname{sgn}\left\{\partial Y^{*} / \partial \delta\right\}=\operatorname{sgn}\left\{-(\beta-\gamma)-\gamma \lambda(n-1) / 2+\gamma \lambda(n-1)\left(\partial W^{*} / \partial \delta\right)\right\} .
$$

The sum of the first two terms is negative for all $\lambda \in[0,1]$. Since $\partial \mathrm{W}^{*} / \partial \delta>0$ for all $\lambda \in[0,1]$, the last term is zero if $\lambda=0$, but it is strictly positive for $\lambda \in(0,1]$. Thus, for $\lambda=0, \partial \mathrm{Y}^{*} / \partial \delta<0$. That is, the interim price charged by a low-quality firm (and its output and profits), when all its rivals are surely selling low-quality products as well, is lower the higher is the loss $\delta$ associated with low quality. This is consistent with our intuition from the complete information model, wherein an increase in the loss $\delta$ causes the low-quality firm to lower its price, because consumers are willing to pay less for products that are known to be of low quality.

However, if $\lambda>0$, so a low-quality firm faces high-quality rivals with positive probability, 
then the final term above comes into play. Moreover, the expression $\partial \mathrm{W}^{*} / \partial \delta$ involves a ratio whose numerator is positive and increases linearly in $\alpha$ and a denominator that is positive and increases with the square root of $\alpha$, while the negative terms are independent of $\alpha$. Thus, for any fixed $\lambda \in$ $(0,1]$, there exists an $\alpha_{\delta \lambda}$ that is sufficiently large to ensure that the positive term $\gamma \lambda(\mathrm{n}-1)(\partial \mathrm{W} * / \partial \delta)$ overtakes the negative constant terms and, thus, that $\partial \mathrm{Y}^{*} / \partial \delta>0$ as claimed in Proposition 6 (iv). 


\section{References}

Bagwell, Kyle. “Pricing to Signal Product Line Quality,” Journal of Economics and Management Strategy 1 (1992), 151-174.

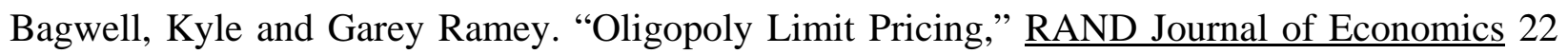
(1991), 155-172.

Bagwell, Kyle and Michael Riordan. “High and Declining Prices Signal Product Quality,” American Economic Review 81 (1991), 224-239.

Bester, Helmut. “Quality Uncertainty Mitigates Product Differentiation,” RAND Journal of Economics 29 (1998), 828-844.

Cho, In-Koo and David M. Kreps. "Signaling Games and Stable Equilibria,” Quarterly Journal of Economics 102 (1987), 179-221.

Das Varma, Gopal. “Bidding for a Process Innovation under Alternative Modes of Competition,” International Journal of Industrial Organization 21 (2003), 15-37.

Daughety, Andrew F. and Jennifer F. Reinganum. “Product Safety: Liability, R\&D and Signaling,” American Economic Review 85, (1995), 1187-1206.

Daughety, Andrew F. and Jennifer F. Reinganum. "Secrecy and Safety,” American Economic

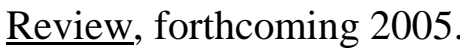

Daughety, Andrew F. and Jennifer F. Reinganum, “Competition and Confidentiality: Signaling Quality in a Duopoly When There is Universal Private Information,” Department of Economics Working Paper No. 04-W17, July 2004; revised January 2005.

Fluet, Claude and Paolo G. Garella. “Advertising and Prices as Signals of Quality in a Regime of Price Rivalry,” International Journal of Industrial Organization 20 (2002), 907-930. 
Gal-Or, Esther. “The Advantages of Imprecise Information,” RAND Journal of Economics 19 (1988), 266-275.

Harrington, Joseph E., Jr. “Oligopolistic Entry Deterrence Under Incomplete Information,” $\underline{\text { RAND }}$ Journal of Economics 18 (1987), 211-231.

Hertzendorf, Mark N. "I’m Not a High-Quality Firm - But I Play One on TV,” RAND Journal of Economics 24 (1993), 236-247.

Hertzendorf, Mark N. and Per Baltzer Overgaard. "Prices as Signals of Quality in Duopoly," Working Paper (2001a).

Hertzendorf, Mark N. and Per Baltzer Overgaard. "Price Competition and Advertising Signals: Signaling by Competing Senders,” Journal of Economics and Management Strategy 10 (2001b), 621-662.

Keeton, W. Page, David G. Owen, John E. Montgomery, and Michael D. Green, Products Liability and Safety, Cases and Materials, $2^{\text {nd }}$ Ed. Westbury, New York: The Foundation Press, Inc., 1989.

Klein, Benjamin, and Keith B. Leffler. "The Role of Market Forces in Assuring Contractual Performance,” Journal of Political Economy 89 (1981), 615-641.

Levin, Dan, James Peck and Lixin Ye, “Quality Disclosure and Competition,” Working Paper, Department of Economics, Ohio State University, January 2005.

Linnemer, Laurent. “Entry Deterrence, Product Quality: Price and Advertising as Signals,” Journal of Economics and Management Strategy 7 (1998), 615-645.

Lutz, Nancy A. “Warranties as Signals Under Consumer Moral Hazard,” RAND Journal of Economics 20 (1989), 239 - 255. 
Mailath, George J. “An Abstract Two-Period Game with Simultaneous Signaling - Existence of Separating Equilibria,” Journal of Economic Theory 46 (1988), 373-394.

Mailath, George J. "Simultaneous Signaling in an Oligopoly Model," Quarterly Journal of Economics 104 (1989), 417-427.

Martin, Stephen. "Oligopoly Limit Pricing: Strategic Substitutes, Strategic Complements," International Journal of Industrial Organization 13 (1995), 41-65.

Mas-Colell, Andreu, Michael D. Whinston and Jerry R. Green. Microeconomic Theory. New York: Oxford University Press, 1995.

Matthews, Steven A. and Leonard J. Mirman. "Equilibrium Limit Pricing: The Effects of Private Information and Stochastic Demand,” Econometrica 51 (1983), 981-996.

Milgrom, Paul and John Roberts. "Price and Advertising Signals of Product Quality,” Journal of Political Economy 94 (1986), 796-821.

Orzach, Ram and Yair Tauman. “Signalling Reversal,” International Economic Review 37 (1996), 453-464. 